

\section{DISCLAIMER}

This report was prepared as an account of work sponsored by an agency of the United States Government. Neither the United States Government nor any agency Thereof, nor any of their employees, makes any warranty, express or implied, or assumes any legal liability or responsibility for the accuracy, completeness, or usefulness of any information, apparatus, product, or process disclosed, or represents that its use would not infringe privately owned rights. Reference herein to any specific commercial product, process, or service by trade name, trademark, manufacturer, or otherwise does not necessarily constitute or imply its endorsement, recommendation, or favoring by the United States Government or any agency thereof. The views and opinions of authors expressed herein do not necessarily state or reflect those of the United States Government or any agency thereof. 


\section{DISCLAIMER}

Portions of this document may be illegible in electronic image products. Images are produced from the best available original document. 
Issued by Sandia National Laboratories, operated for the United States Department of Energy by Sandia Corporation.

NOTICE: This report was prepared es an account of work sponsored by an agency of the United States Government. Neither the United States Government nor any agency thereof, nor any of their employees, nor any of their contractors, wubcontractors, or their employees, makes any varranty, express or implied, or assumes any legal liability or responsibility for the accuracy, completeness, or usefulness of any information, apparatus, product, or pro cess disclosed, or represents that its use would not infringe privately owned rights. Reference herein to any specific commercial product, process, of eervice by trade name, trademark, manufacturer, or otherwise, does not necessarily constitute or imply its endorsement, recommendation, or favorin by the United States Government, any arency thereof or any of theis b the contractors or subcontractors. The views and opinions expressed herein do not necessarily state or refiect those of the United States Government, any agency thereof or any of their contractors or aubcontractora.

Printed in the United States of America Available from

National Technical Information Service U.S. Department of Commerce

5285 Port Royal Road

Springfield, VA 22161

NTIS price codes

Printed copy: A05

Microfiche copy: A01 


\title{
DIFFUSION BONDING OF STRATAPAX FOR DRILL BITS
}

\author{
John N. Middleton \\ W81 Development Division, 9344 \\ John T. Finger \\ Geothermal Technology \\ Development Division, 9741
}

\section{ABSTRACT}

A process has been -developed for the diffusion bonding of General Electric's Stratapax ${ }^{B}$ drill blanks to support studs for cutter assemblies in drill bits. This report describes the diffusion bonding process and provides bond strength test data for a variety of materials. The extensive process details, provided in the Appendices, should be sufficient to enable others to successfully build diffusion-bonded drill bit cutter assemblies.

R - Registered trademark of Genera1 Electric

\section{DISCLAIMER}

This report was prepared as an account of work sponsored by an agency of the United States Government. Neither the United States Government nor any agency thereof, nor any of their employees, makes any warranty, express or implied, or assumes any legal liability or responsibility for the accuracy, completeness, or usefulness of any information, apparatus, product, or process disclosed, or represents that its use would not infringe privately owned rights. Reference herein to any specific commercial product, process, or service by trade name, trademark, manufacturer, or otherwise does not necessarily constitute or imply its endorsement, recommendation, or favoring by the United States Government or any agency thereof. The views and opinions of authors expressed herein do not necessarily state or reflect those of the Irnitad States finvernment or anv agencv thereof. 


\section{ACKNOWLEDGMENTS}

This work was supported by the U.S. Department of Energy under Contract DE-AC04-76DP00789. The Sandia National Laboratories' technical work was performed by the Geo Energy Technology, Electromechanical Subsystems, Metallurgy and

Fabrication Development Departments. 
Page
$\ldots \ldots \ldots \ldots \ldots \ldots \ldots$

Abstract $\ldots \ldots \ldots \ldots \ldots \ldots \ldots \ldots \ldots \ldots \ldots \ldots \ldots \ldots \ldots \ldots \ldots \ldots$

Introduction and Background $\ldots \ldots \ldots \ldots \ldots \ldots \ldots \ldots \ldots \ldots \ldots \ldots$

Gas Pressure Diffusion Bonding Process - Outline .............11

Investigation of Alternate Stud Materials $\ldots \ldots \ldots \ldots \ldots \ldots \ldots \ldots$

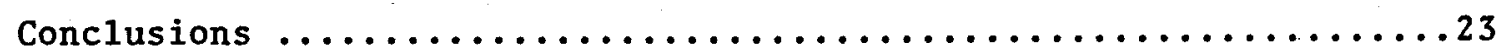

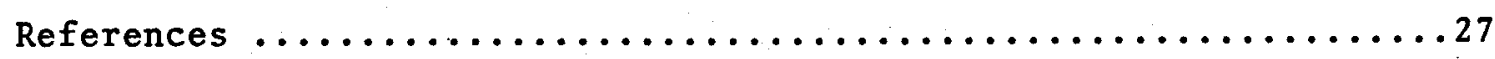

Appendices

A - Preparation of Bonding Surfaces .......................

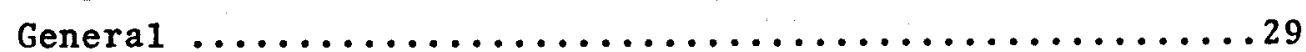

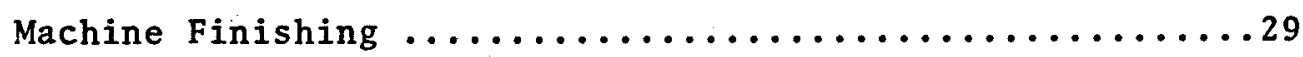

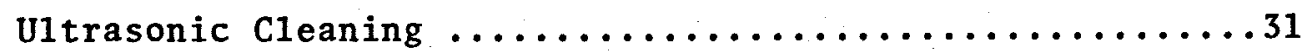

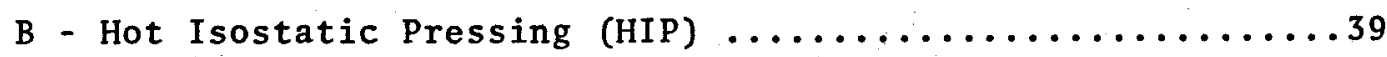

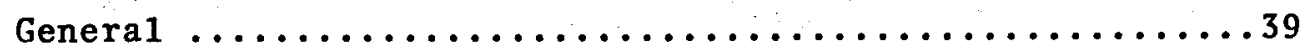

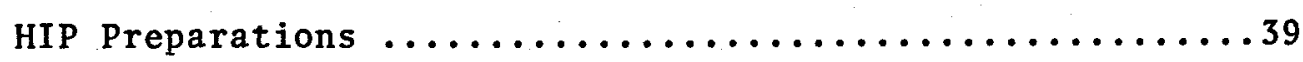

HIP Process Variables ...................... 54

Cutter Assembly Cleanup ................... 58

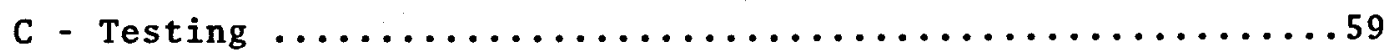

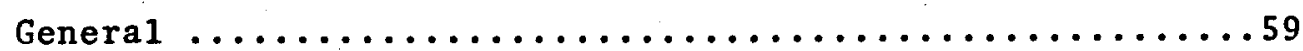

Non-Destructive Testing ....................... 59

Destructive Testing .......................67

Test Results .......................... 

INTRODUCTION AND BACKGROUND

Although the three-cone roller bit dominates the drilling industry, it is not well suited for use at high rotary speeds or high temperatures. Both of these conditions are damaging to the seals and bearings in the bit and lead to early failure. Increased interest in downhole drilling motors (which usually run at least 300 RPM) and geothermal drilling (with bottom-hole temperatures above $275^{\circ} \mathrm{C}$ ) has led to a renewed appreciation of drag bits, which have no moving parts. Until recently, the cutting elements in drag bits have been either tungsten carbide or natural diamonds, but they have been challenged by General Electric's man-made polycrystalline diamond called Stratapax. The man-made product resists wear and abrasion almost as we11 as natural diamond, but because of the random polycrystalline orientation it doesn't have the cleavage planes and directional weakness of natural diamond. Furthermore, the Stratapax can be made in convenient sizes (e.g., over .500 inch diameter) and shapes (flat disc) impossible for natural diamond.

Previous reports (Refs. 1 and 2) have shown that the diffusion bonding of Stratapax drill blanks is feasible and results in a high quality welded interface. This report provides an update on the diffusion bonding investigation, and its prime purpose is to provide a record of a preferred set of processes.

The Stratapax drill blank, as furnished by General Electric, is a composite of a layer of man-made polycrystalline diamond and a layer of cermet material. The cermet is tungsten carbide (WC) in a cobalt matrix. GE produces a variety of sizes and shapes in their Stratapax drill blank product line; the drill blank used in the Sandia process (type $2530 \mathrm{NC}$ ) is 0.524 inch in diameter and 0.139 inch thick (see Figure 1). The diamond layer is approximately 0.020 inch thick and the balance is the cermet. 


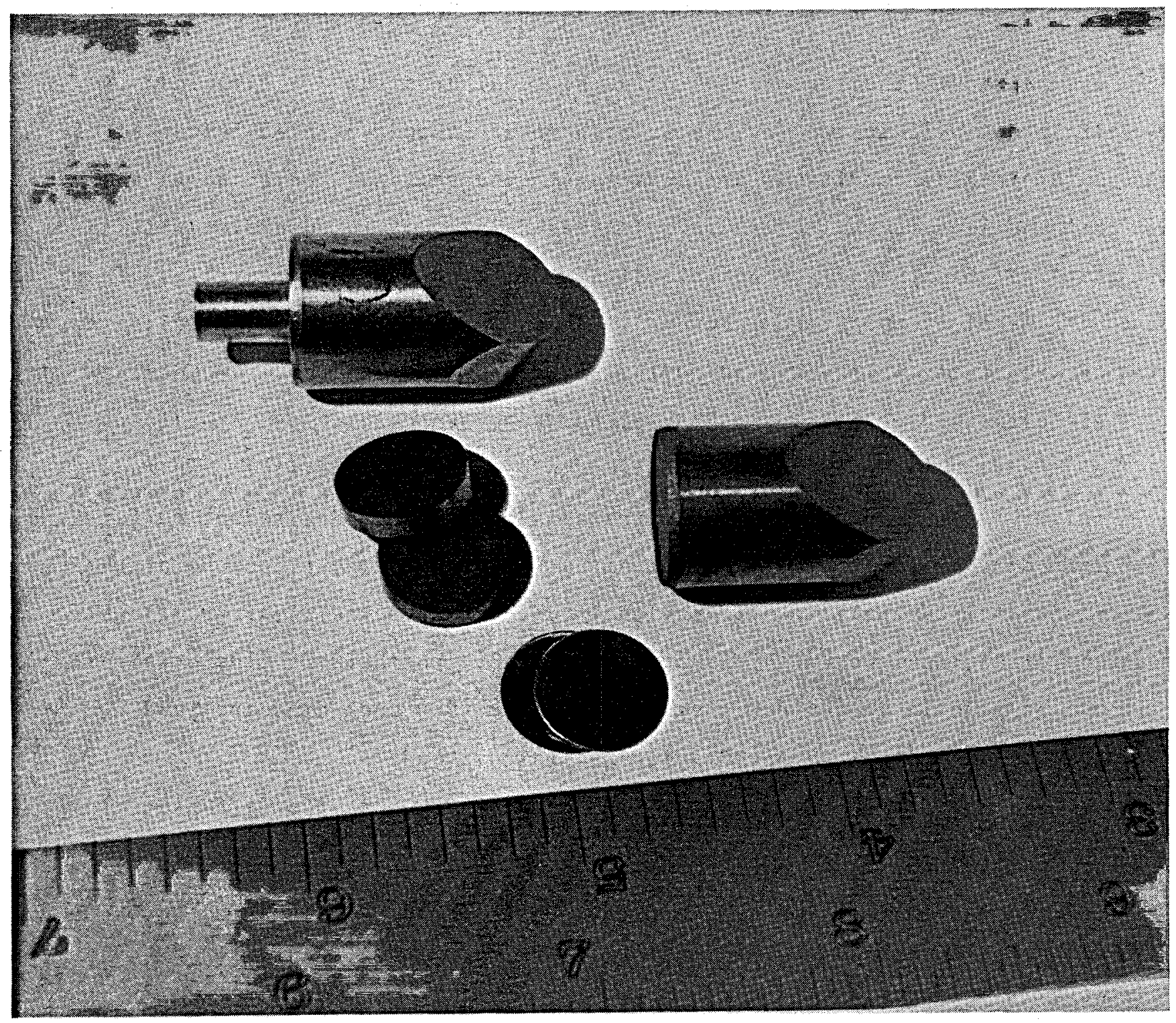

Figure 1. Stratapax drill blanks

(note black layer of

sintered diamond) with

stee 1 and WC studs and

with nickel foil discs. 
The drill blank can be mounted directly on the bit body or can be attached to a support stud which then is mounted in the bit. Stud mounted cutters are much more versatile in allowing changes to the cutter location, standoff, rake angle, etc. so most of Sandia's development has been focused on this design.

The two kinds of studs used for the majority of the Sandia development work are also pictured in Figure 1. The tungsten carbide studs are of the correct size for direct assembly into a drill bit, but because the steel studs require clean-up machining after bonding they are oversize in diameter and length and include a machining holding shaft. Some steel studs also have an optional cavity made in the bonding surface with a $9 / 16$ inch end mill. This feature helped maintain the proper Stratapax location during bonding.

Although there are several ways that drill blanks can be attached to bit bodies or studs (Ref. 1), brazing and diffusion bonding have received the most attention. Early bits and cutter assemblies used a low-temperature braze with a shear strength of about $35,000 \mathrm{psi}$ and fracture of the braze joint was a common failure in these units. The objective of Sandia's bonding study was the development of a technique that would assure joint efficiencies adequate for high performance bits.

Diffusion bonding was chosen as the candidate for extensive development because of its very high joint efficiencies (shear strength over 70,000 psi).

Diffusion bonded drill bit cutter assemblies are shown in Figure 2. The tungsten carbide cutter assembly has been cleaned after bonding, and the steel cutter assembly has been machined to size for drill bit assemb1y.

Fina11y, completed stratapax drill bits are shown in Figure 3. These drill bits, which actually contain a mixture of brazed and diffusion bonded cutter assemblies, were used in a special evaluation test that is reported in Ref. 5 


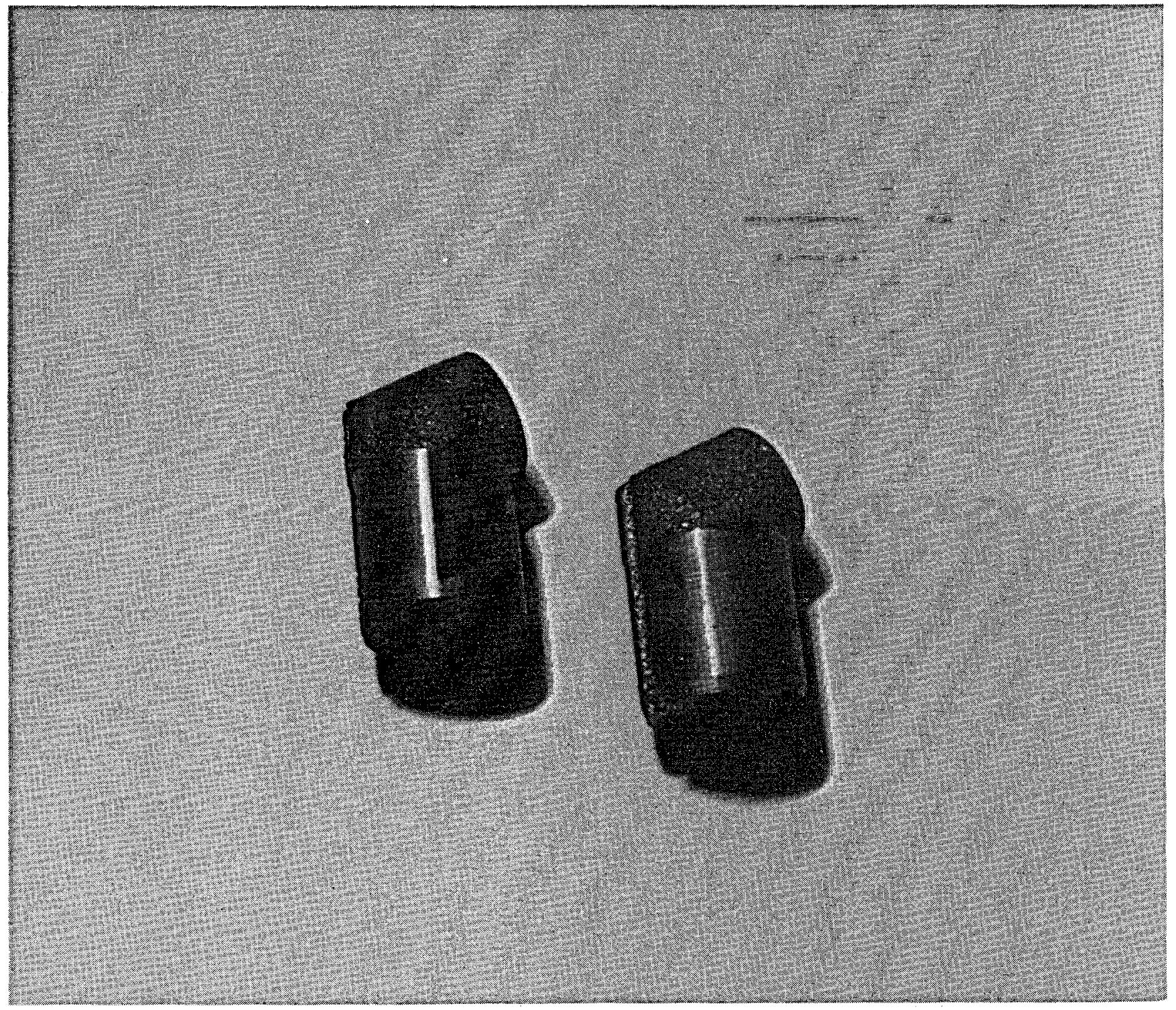

Figure 2. Tungsten Carbide (1eft) and Steel Stud Cutter Assemblies. 
There are many diffusion bonding variables which can be combined in a variety of ways to provide different and yet acceptable processes. During the past two years, the need to provide several hundred Stratapax cutter assemblies in support of drill bit testing has resulted in a preferred process that is detailed in this report. It is based on the following general criteria:

1) Start with (or create) known surface conditions of the parts to be bonded.

2) Minimize the number and complexity of the process steps consistent with achieving the required bond strength.

3) In each process step, use rigorous controls to assure consistency.

We emphasize that the process detailed here does not produce maximum attainable diffusion bond strength. Rather, this process produces adequate strength yet minimizes cost by minimizing both time and specialized equipment requirements. Laboratory and field tests have shown that the bond strengths produced by this process are more than sufficient for drill bit applications. 
GAS PRESSURE DIFFUSION BONDING PROCESS - OUTLINE

Genera1

Diffusion bonding is a solid phase welding technique. The materials to be welded are brought together under pressure, and an elevated temperature causes diffusion of surface impurities and base materials-resulting in a weld of the two materials. Diffusion bonding requires faying surfaces to be brought within $10 \AA$, therefore, the diffusion bonding processes must minimize oxides and/or utilize materials capable of absorbing oxygen.

The chemical and metallurgical criteria for materials selection for diffusion bonding is beyond the scope of this report, however, the control of oxide thickness is the essence of the process described here. Basically, the process involves the following two oxide-controlling steps:

1. Machine the faying surfaces of the base materials to erase the previous, and usually unknown, oxide formation history.

2. Perform the subsequent steps of the diffusion bonding process to minimize oxide formation in the room ambient steps and to minimize the amount of oxygen present in the high temperature steps.

With any welding process, it is necessary to consider the materials being welded. In this case, one material is fixed, the Stratapax tungsten carbide (WC) cermet, and only the stud material remains to be specified. There are two general cases of stud materials that require different treatment:

Ist case - materials that flow under pressure. Steels undergo solid state plastic deformation when subjected to the pressure and temperature used in this process. 
2nd case - materials such as tungsten carbide that do not flow under the process conditions.

As a result of this fundamental difference in behavior some of the process steps are different for steel and for tungsten carbide studs.

\section{Process Steps}

This section summarizes the process. Brief comments provided in this section outline the more important points, and the process details are found in the referenced appendices.

I. Preparation of Bonding Surfaces (see Appendix A for details)

A. General Requirements. Minimize the storage time of parts between steps of the process, handle clean parts only with clean tools or clean gloves, and minimize parts exposure to moist air and/or elevated temperature.

B. Machine Finishing.

1. Tungsten carbide surfaces (e.g., Stratapax drill blanks and WC drill bit studs): Grind faying surface to obtain a surface finish of 10 microinches RMS or better and a flatness of 200 microinches or better.

2. Steel studs: Grind or machine faying surface to obtain a surface finish of 50 microinches RMS or better and a flatness of 1000 microinches or better.

3. Post machining: After the machine cut of the faying surface, the parts require the care outlined in the general requirements above.

C. Ultrasonic Cleaning.

1. Clean all parts (and part handling equipment) by a multistage ultrasonic process. After the last cleaning solution, blow excess liquid from parts with dry nitrogen.

2. Place parts in clean, covered glass dishes and store in either a vacuum or a well desiccated dry box. 
II. Hot Isostatic Pressing (HIP) (see Appendix B for details)

A. General. The HIP method is used to provide simultaneous heat and pressure. This process is performed in an autoclave, and the high gas pressure required dictates the use of equipment found only in laboratories specializing in HIP.

B. Preparation for HIP. Appendix B has photographs of the equipment used for this process. Very briefly, the steps are:

1. Position the surfaces to be welded together and wrap this assembly in thin copper foil. (The foil prevents the pressure medium from intervening between the parts to be bonded.)

a. Stratapax to WC studs. Prior to wrapping the parts together, place a .002 or .003 inch thick $\mathrm{Ni}$ foil shim in the bond line. (The Ni flows during HIP and forms the weld interface over the entire area. WC does not flow, and without the Ni only a few high points would be welded.)

b. Stratapax to steel studs. Steel flows during HIP, therefore, an intermediate layer (e.g., Ni foil) is not required. However, as discussed in the conclusions section of this report, there is evidence that a thin $\mathrm{Ni}$ layer enhances the toughness of the weld with only a small sacrifice in ultimate shear strength.

2. Prepare steel containers that will be used to hold the parts in the autoclave. (Mild steel is used to permit some container collapse without rupturing.)

3. Completely fill the steel containers, surrounding the foil-wrapped assemblies with granulated graphite. (The graphite serves as the pressure transmitting medium.)

4. Evacuate the containers and weld closed. (Oxygen that is in the container during HIP causes the formation of low-strength metal oxides which may be too thick to be absorbed, thereby causing low strength diffusion bonds.) 
C. HIP parameters and behavior.

1. For this diffusion bonding process, the HIP temperature and pressure of $675^{\circ} \mathrm{C}$ and 30,000 psi are held for six hours.

2. The steel container partially collapses to the point that the graphite granules have been compacted to equilibrate the internal and external pressures. The copper foil around each assemb1y prevents the graphite from invading the joint being welded. Thus, the parts are squeezed uniformly (isostatical1y) on a11 exterior surfaces, and the faying surfaces are held in intimate contact by this pressure. This pressure, coupled with the elevated temperature, results in the diffusion weld of the surfaces.

D. Assembly cleanup. The copper foil wrap welds sufficiently we11 to the steel and carbide studs that cleanup is not trivial. The best way to clean copper from the carbide studs is a careful, partial immersion in nitric acid. The steel studs are most readily machined, and, for that purpose, diameter and length allowances are provided initially on the steel studs. After cleanup, the cutter assemblies are ready for drill bit assembly.

III. Testing (see Appendix $C$ for details

A. General. Testing is a vital step in the process because of the importance of quality control and the difficulty of knowing anything about bond strength from a simple inspection. In the development of the diffusion bonding process, special emphasis on testing was necessary because many of the process steps were new and their effects had not been evaluated.

Both destructive and non-destructive techniques were used to evaluate the bonding process.

In the destructive tests the bonded cutter assemblies were placed in a fixture that loaded the bond in shear. Clearances between the cutter and the fixture allowed some bending component 
in the 1oad, so that the failures did not truly represent the ultimate shear strength. As long as the tests were consistent, however, they could be used to measure changes in strength caused by process variables. Another aspect of this testing was that the fracture sometimes occurred in the drill blank or in the stud. If the stud or blank cracked, the bond was considered to be good unless the failure was at an unually low value.

Once the destructive tests had been used to validate a specific process, some type of non-destructive inspection was used on the cutters intended for bits or other experiments. The quickest and simplest inspection is ultrasonic, but its information is mostly negative. That is, a bad ultrasonic signal is sure to indicate a bad bond, but a good ultrasonic signal doesn't guarantee a good bond. For this reason, many of the cutters that passed the ultrasonic inspection then received a sub-failure shear test. This used the same fixture as the destructive test but the 10 ad was about $2 / 3$ of the failure value. This served as an adequate check of the bond strength because if a bond was bad, it was most likely to be very bad, not just slightly degraded. The sub-failure shear testing is time consuming and expensive, but it is necessary when ultimate reliability is required or when process consistency hasn't been demonstrated. 


\section{INVESTIGATION OF ALTERNATE STUD MATERIALS}

\section{Background}

Although Sandia's experience in the testing of Stratapax drill bits has not been extensive, we have verified the obvious need for a high modulus, hard, and tough drill bit stud. Carbide studs do not meet the toughness requirement and sometimes fracture in use. Although steel studs have a lower modulus than carbide, they are much tougher and they offer the potential for easier bit repair. A carbide stud is extremely difficult to remove from a bit body, but a broken or worn steel stud could be replaced in the field. Sandia selected 4340 steel for studs because of its availability and its good mechanical properties, however, 4340 anneals when subjected to the HIP temperature. It appeared that drill bits using 4340 steel studs experienced increased macrochipping of the diamond when used in medium hard rock. It may be that the more rapid friction wear across the crown of the steel studs resulted in less structural support for the Stratapax, and caused accelerated Stratapax wear.

\section{Test Configuration}

Sandia evaluated several materials' suitability for diffusion bonding. Two nickel alloys, five steel alloys, and two types of bond line foil were selected. This evaluation was performed at the end of the funded development program, and as a result only 2 or 3 samples of each type were tested to destruction. Actual drill bit cutter assemblies and fullscale drill bits were not tested.

These samples were a special test configuration and required a special test fixture. (See Figure 4.) The samples were made of GE's 883 W alloy (which is metallurgically similar to the Stratapax substrate, but much cheaper) and the stud material to be evaluated. The WC and the candidate stud material were of different diameters which allowed a 


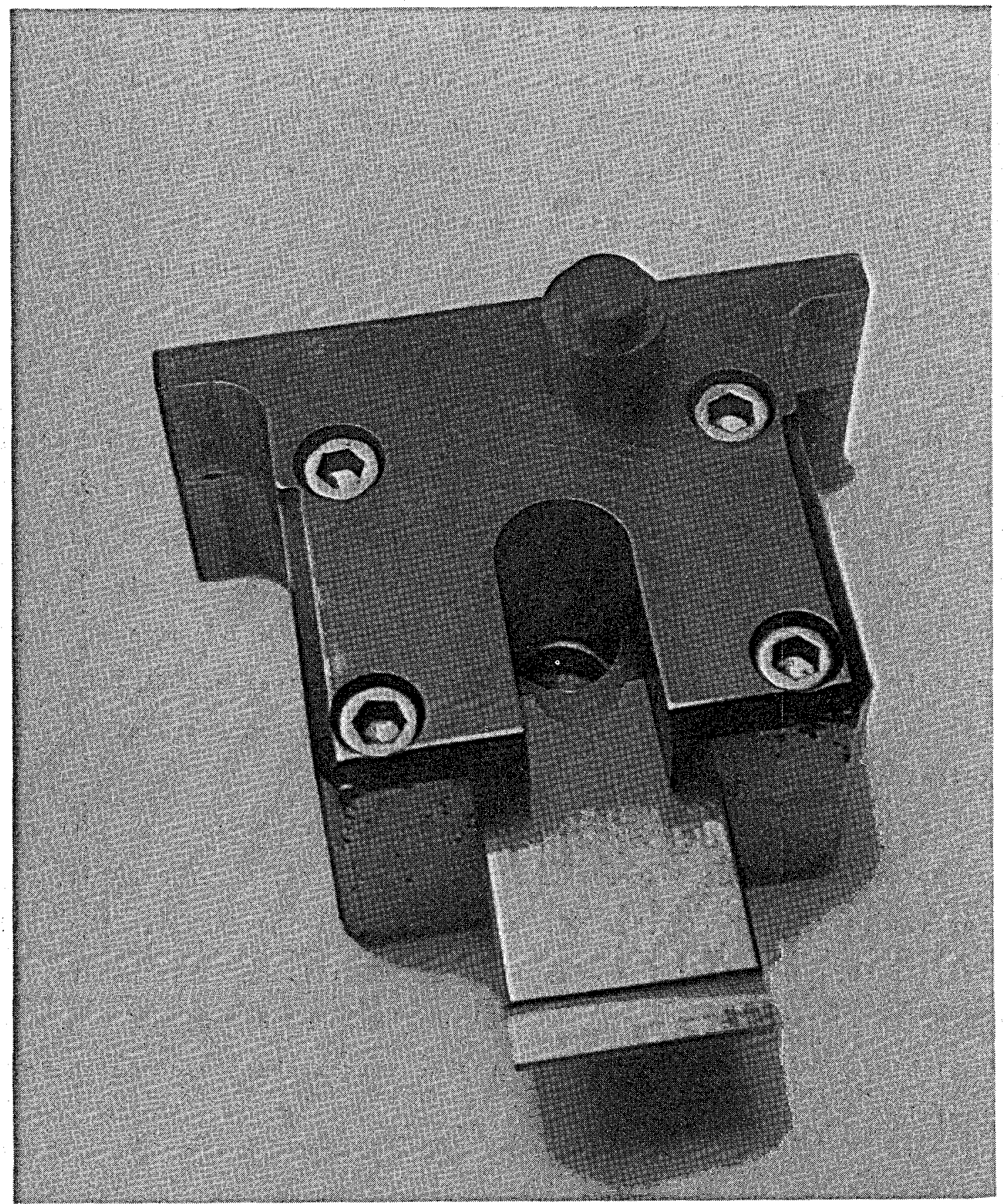

Figure 4. Shear Test Fixture with Material Sample.

Sma11 diameter of sample is WC button;

large cylinder is candidate stud material. 
small compression spring in the fixture base to seat the bond line precisely at the fixture shear plane. In addition, close tolerances were used to maintain a sample-to-fixture clearance of .0002 to .0006 inch on the diameter. Of course the closer the fit, the less test sample cocking and the lower the bending moments; as a result, the measured ultimate shear strength was higher than in tests of actual drill bit cutter assemblies.

\section{Test Resu1ts}

The ultimate shear strengths for the seven candidate stud materials are given in Table 1. Note that, in general, the bare metals provide the strongest bonds. Our experience with drill bit stud assemblies shows, however, that foil in the bond line interface may result in a tougher bond with better survivability under impact and bending loads. A notably high strength was achieved with 9-4-20 steel and Ti foil. Other 9-4 series steels with even higher carbon contents are also interesting candidates but were not tested.

Table 2 gives hardness and oxide forming characteristics of these same materia1s. The toughness (not strength) of all seven candidate materials is much higher than WC, so high post-HIP hardness is the goal (i.e., if relatively brittle WC studs survive drilling environments, then brittleness of steel studs should not be a concern).

Table 3 provides the pre-machining heat treatments used on these materials. 
TABLE 1

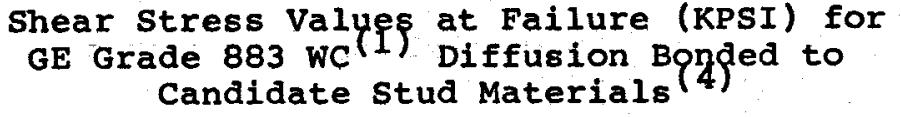

stud Material

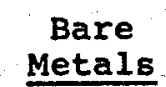

73

77

79

84

76

9-4-20

Hastelloy B2 (2)

Monel $\mathrm{K5} 0 \mathrm{O}^{(2)}$
$0^{(3)}$

63
.003

Ni Foil

54

64

68

57

64

$25^{(3)}$

58
$.002^{(5)}$

Ti Foil

56

69

63

71

86

68

62

Notes: (1) Grade 883 WC similar to stratapax. Stress values are avg. of 2 to 3 samples each type.

(2) Nickel alloys.

(3) Results indicate poor material combinations for diffusion bonding.

(4) The 883 blanks were also bonded to wC studs and tested, but defective test fixtures gave unreliable data. In a good bond the shear failure occurs in the bond line foll, so the strength with the WC studs should not differ greatiy from the steel studs.

(5) Although these experiments indicated that $\mathrm{Ti}$ foll bonds are stronger than $\mathrm{Ni}$, all the process development was done with $\mathrm{Ni}$ foil. We do not have enough data to know whether there are bonding process problems unique to Ti foil. 
TABLE 2

Stud Material Characteristics

Material

ASTM A710

4340

4820

Maraging 250

$9-4-20$

Hastelloy B2

Monel K500

\begin{tabular}{|c|c|c|c|}
\hline $\begin{array}{l}\text { Pre- } \\
\text { HIP } \\
\end{array}$ & $\begin{array}{l}\text { Post- } \\
\text { HIP } \\
\end{array}$ & $\begin{array}{c}\text { Post- } \\
\text { Cleaning }\end{array}$ & $\begin{array}{l}\text { Post- } \\
\text { HIP } \\
\end{array}$ \\
\hline 20 & 13 & Yes & $-\infty$ \\
\hline 25 & 17 & Yes & -- \\
\hline 22 & 28 & No & No \\
\hline 39 & 35 & No & No \\
\hline 36 & 40 & No & Yes \\
\hline 29 & 14 & No & Yes \\
\hline 30 & 35 & No & No \\
\hline
\end{tabular}

Notes: (1) Higher post-HIP haraness indicates higher material strength and improved wear characteristics.

(2) Visual oxides are thick enough to be potential problem. Oxide thicknesses not measured so can't tell if HIP made A710 and 4340 worse. Post-HIP oxide also a potential problem, however, the Titanium foil. (an oxygen getter) can minimize problem (Table 1 shows 9-4-20 and Hastelloy B2 increased in shear strength with bond line $T i$ foil). 
TABLE 3

Stud Material Heat Treatments

\begin{tabular}{|c|c|}
\hline ASTM A710: & $\begin{array}{l}1650^{\circ} \mathrm{F} \text { for } 1 \mathrm{hr} \text {, water quench; } \\
\text { age for I hour at } 1200^{\circ} \mathrm{F} \text {, air cool }\end{array}$ \\
\hline 4340: & $\begin{array}{l}1525^{\circ} \mathrm{F} \text { for } 1 / 2 \mathrm{hr} \text {, oil quench; temper } \\
\text { for } 1 \text { hour at } 1200^{\circ} \mathrm{F} \text {, air cool }\end{array}$ \\
\hline 4820: & $\begin{array}{l}1500^{\circ} \mathrm{F} \text { for } 1 \mathrm{hr} \text {, oil or water quench; } \\
\text { temper for } \mathrm{l} \text { hour at } 1150^{\circ} \mathrm{F} \text {, air cool }\end{array}$ \\
\hline Maraging $250:$ & $\begin{array}{l}1550^{\circ} \mathrm{F} \text { for } 1 \text { hour, air cool; age for } \\
2 \text { hours at } 1200^{\circ} \mathrm{F} \text {, air cool }\end{array}$ \\
\hline $9-4-20:$ & $\begin{array}{l}1550^{\circ} \mathrm{F} \text { for } 1 \mathrm{hr} \text {, water quench, temper } \\
\text { for } 2 \text { hours at } 1200^{\circ} \mathrm{F} \text {, air cool }\end{array}$ \\
\hline Hastelloy B: & $\begin{array}{l}1950^{\circ} \mathrm{F} \text { for } 1 \text { hour, water quench; age } \\
\text { for } 6 \text { hours at } 1200^{\circ} \mathrm{F} \text {, air cool }\end{array}$ \\
\hline Monel K-500: & $\begin{array}{l}1800^{\circ} \mathrm{F} \text { for } 1 \text { hour, water quench; age } \\
\text { for } 16 \text { hours at } 1100^{\circ} \mathrm{F} \text {, furnace cool } \\
\text { at } 15^{\circ} \mathrm{F} \text { to } 25^{\circ} \mathrm{F} \text { per hour to } 900^{\circ} \mathrm{F} \text {, } \\
\text { air cool from } 900^{\circ} \mathrm{F} \text { (Note: } 50^{\circ} \mathrm{F} \\
\text { steps for } 2-1 / 2 \mathrm{hr} \text { each may be used } \\
\text { in place of furnace cooling from } 1100^{\circ} \mathrm{F} \\
\text { to } 900^{\circ} \mathrm{F} . \text { ) }\end{array}$ \\
\hline
\end{tabular}




\section{Summary of Results}

A1though the sample size in this experiment was sma11, a11 processes were closely controlled and the results should be representative. Some of the material characteristics are:

1. ASTM A710 - Low post-HIP hardness and the formation of oxide in the cleaning process make this material unattractive.

2. 4340 - Same problems as with A710. Although used in Sandia drill bits, this steel must still be considered unattractive when compared with some of the other materials tested.

3. 4820 - Interesting with a bare or $\mathrm{Ni}$ bond 1 ine interface. Also had no visual oxide problems. Perhaps some pre-HIP heat treat variations could help increase the post-HIP hardness. A good candidate for drill bit studs.

4. Maraging 250 - Has a high post-HIP hardness and has very high bond strengths with a bare metal or Ti bond interface. A1so, like 4820 , did not have visual oxide problem. Another good candidate for drill bit studs.

5. 9-4-20 - Highest hardness of all plus highest bond strength when $\mathrm{Ti}$ is in the bond interface. The reason for the high bond strength with $\mathrm{Ti}$ foil is noted in Table 2. The formation of the visual oxide during HIP makes one suspect that small relaxations in process control may cause disastrous diffusion bonding variations. Perhaps an oxygen getter in the HIP container would eliminate the visual oxide. Further experiments are required to evaluate this material.

6. Hastelloy B2 - Overall a poor material for diffusion bonding and certain1y not a good candidate for drill bit studs.

7. Monel K500 - Good, but not superior, bond strengths. Post-HIP hardness is very good, and there is a lack of visual oxides. All in a11, a good candidate for dri11 bit studs.

Note that the conclusions are based solely on material properties and bond characteristics. If material availability and cost are considered, there may be a change in desirability of the different materials. 


\section{CONCLUSIONS}

Both laboratory and field tests have shown that diffusion-bonded drill bit cutter assemblies have sufficient strength to withstand drilling environments. A properly diffusion-bonded cutter assemb1y will maintain its weld integrity until gross wear or fracture failure occurs to the Stratapax and/or stud.

Successful diffusion bonding does require careful process control. The diffusion bonding requirements are really not different from the requirements for brazing, in that both processes require control over surface contaminants, temperature level, and time of temperature application.

Although not statistically verified, the following conclusions are supported by consistent observations in both laboratory and field tests over a period of several years.

1. Diffusion welding is easier with steel studs than with tungsten carbide studs, but the bonds of Stratapax to carbide studs are slightly stronger than the bonds to steel studs.

2. Tungsten carbide studs require more stringent surface finish, and still one can expect cracks in many (perhaps 25\%) of the cutter assemblies. There will be one to three nearly microscopic cracks extending across the face of the stratapax and completely through the diamond and the tungsten carbide substrate. However, there has been no evidence that these cracks cause a premature failure, or are even the source of failure when a cutter assembly is loaded beyond the gross failure point.

3. When bonding to steel studs, the stee1 surface finish requirements are not stringent.

a. With bare steel, the bond strength of a cutter assembly improves as the steel surface finish improves. However, a finely ground surface ( 8 microinches roughness and a .0002 inch flatness) 
is only about $20 \%$ stronger than a machined surface $(64$ microinches and .0009 inch).

b. If a Ni layer is in the bond line, the shear strength with the rougher, machined surface is about $10 \%$ higher than with the smooth, ground surface.

4. A layer of nickel in the bond line may slightly reduce the bond strength compared to bonding Stratapax directly to stee1; however, the nickel layer provides a bond toughness that could enhance downhole cutter survivability.

5. The strength of a good diffusion bond is about twice that of a low temperature braze, but is roughly equal to that of GE's high temperature LS braze at room temperature. This statement implies two further questions:

Is it equally easy to produce a good diffusion bond and a good LS braze joint?

Does the strength of the two kinds of joint remain comparable as the temperature increases?

Unfortunately, we do not have conclusive answers to those questions. Both joining processes are very sensitive to contamination and it is difficult to ensure consistency in the contaminant-reducing process steps. Brazing requires less expensive facilities than the complete diffusion process, but if the HIP steps are done by an outside supplier the in-house diffusion bonding equipment is fairly simple. A1so remember that, although Sandia produced several hundred diffusion bonded cutter assemblies, our output was small compared to a bit manufacturer's requirements. If the diffusion bonding process described here were extended to a production line (perhaps automated) operation, improved consistency might make the process more attractive.

There is some theoretical reason to believe that diffusion bonds will be stronger than brazed joints at high temperature. This agrees with field tests on bits with both kinds of cutter assembly in the same 
bit. In the tests with severe heat degradation, the brazed cutters came off the studs before the diffusion bonded ones. The bonded cutter assemblies have never been shear tested at high temperature, so there is no quantitative data relating strength to temperature for diffusion bonds. In fact, there have been no laboratory tests at any temperature reported in published literature which give direct strength comparisons of LS brazed and diffusion bonded cutter assemblies. 


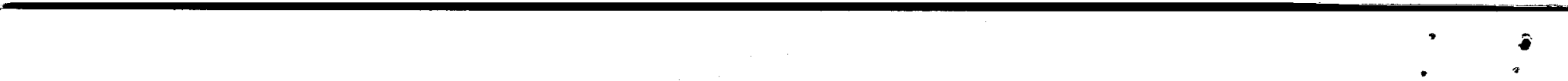




\section{REFERENCES}

1. Jellison, J. L., "Gas Pressure Bonding of Stratapax," ASME Paper No. 77-Pet-72, presented September 1977, at the Energy Technology Conference of the ASME, Houston, TX.

2. Jellison, J. L. and C. F. Huff, "A Review of Attachment of Stratapax Using Gas Pressure Diffusion Bonding," Sandia National Laboratories Report SAND78-0318C, 1978.

3. Huff, C. F., J. L. Jellison, and S. G. Varnado, "Bonding Technique Attaches Stratapax to Dri11 Bits," Oil and Gas Journa1, February 19, 1979, pp. 111-114.

4. Pope, L. E., "Analysis of Failed Stratapax-Stee1 Stud Cutter Elements," Sandia National Laboratories Report SAND80-0410, 1981.

5. Hoover, E. R. and J. N. Middleton, "Laboratory Evaluation of PDC Drill Bits Under High-Speed and High-Wear Conditions," Journal of Petroleum Technology, December 1981, pp. 2316-2321.

6. Jellison, J. L., "Effect of Surface Contamination on Solid Phase Welding - An Overview," from Surface Contamination, vo1. 2, edited by K. L. Mittal, Plenum Publishing Corp., 1979.

7. "Geothermal Technology Development Program - FY'81 Annua1 Report," Kelsey, J. R., editor, Sandia National Laboratories Report SAND812124 , sections $3.1,3.7,3.16$. 
APPENDIX A

PREPARATION OF BONDING SURFACES

GENERAL

This appendix gives the detailed process steps that will provide clean surfaces that have an acceptably small amount of meta11ic oxide. This appendix is in two parts, machine finishing and ultrasonic cleaning. A special caution: some machining coolants contain sulfur. Sulfur is one contaminant that is almost impossible to eliminate and can cause braze as well as diffusion bond failure. There are plenty of coolants that do not contain sulfur--use them.

\section{MACHINE FINISHING}

\section{Stratapax Dri11 Blanks}

GE grinds the faying surface and the outside cylindrical surface. However, the amount of material GE removes from the faying surface has varied over the years. After several years with no Stratapax interior defect problems, some Sandia test sample failures occurred in the Stratapax cermets adjacent to the faying surface. The failed Stratapax were 0.139 inch thick, whereas the earlier Stratapax were 0.133 inch thick. Some defects were found in the Stratapax cermets several mils beneath the surface (see Reference 4). To help assure that:

1) process damaged, subsurface Stratapax material is removed, and

2) the subsequent bonding process starts with a known and controlled surface,

approximately 0.005 inch of cermet should be removed by grinding the Stratapax drill blanks.

The Stratapax surface requirements that Sandia has used successfully are a finish of 10 microinches or better and a flatness of 200 microinches or better. If the Stratapax are to be bonded only to steel studs, 
then the surface requirements can probably be safely relaxed by a factor of 2 , if necessary. Independent of finish, a low material removal rate and adequate coolant must be used to minimize oxide formation. (Unacceptable oxide thicknesses will form long before the onset of material heat damage.) After grinding, the drill blanks must not be handled with bare hands or dirty tools, and must be stored in a clean, protective environment.

The preferred Stratapax process details used by Sandia are:

1. Use a freshly dressed 180 to $250 \mathrm{grit}$, resin bonded, 100 concentration diamond grinding wheel and a liberal flow rate of Sim Coo1 5 Star 40, water soluble coolant.

2. Use a wheel speed of $3450 \mathrm{RPM}$ ( 6 inch diameter) with a table speed of 80 inches per minute and a cross feed rate of 0.005 inch to .015 inch per stroke.

3. Maximum depth of cut 0.002 inch for roughing and 0.0002 inch for finishing. Remove 0.005 inch total from Stratapax thickness.

4. Immediately after grinding, and using clean gloves or tools, thoroughly rinse Stratapax in running tap water, shake off excess water, and store in a covered container of reagent grade isopropy1 alcoho1.

\section{Studs}

For tungsten carbide studs, the finish requirements are 10 microinches roughness and 200 microinches flatness. For stee1 studs, 50 microinches roughness and 1000 microinches flatness should be the goal. As with Stratapax, machining temperature control and post machining handling and storage cleanliness are important.

Inspecting the machined studs and deburring the steel studs create additional contamination risks. Sandia experience is that the ultrasonic cleaning specified in the next section adequately removes the 
majority of the contaminants experienced in machine shops and inspection rooms, including fingerprints. It is tempting to say that post machining cleanliness is really not important, but widespread experience at Sandia shows that eliminating the contamination source is better than relying on its removal in cleaning.

\section{ULTRASONIC CLEANING}

\section{Genera1}

This section on ultrasonic cleaning contains a cleaning procedure, a list of required chemicals, and a set of general instructions for operating the cleaning equipment shown in Figure $A-1$.

\section{Cleaning Chemica1s}

The following list of chemicals are used in the ultrasonic cleaning of the Stratapax and studs (the bond line $\mathrm{Ni}$ foil is discussed separately):

1. Distilled water

2. Isopropyl alcoho1, reagent grade

3. Trichloroethylene, reagent grade

4. Dry nitrogen gas with a $-80^{\circ} \mathrm{F}$ dewpoint. (Note: To avoid contamination, do not use gas from high pressure cylinders after the pressure has dropped below 500 psi.)

\section{Cleaning Procedure}

The following cleaning steps are to be used for Stratapax and studs:

1. a. (Parts that were machined using oil-base coolants.) U1trasonic clean in trichlorethylene for 1 to 2 minutes.

b. (Parts that were machined using water-soluble coolants.) U1trasonic clean in distilled water for 1 to 2 minutes.

c. (If machining coolant is unknown.) Perform step a. and then step $b$. above.

2. Slosh rinse in alcohol.

3. U1trasonic clean in trichloroethylene for 1 to 2 minutes. 


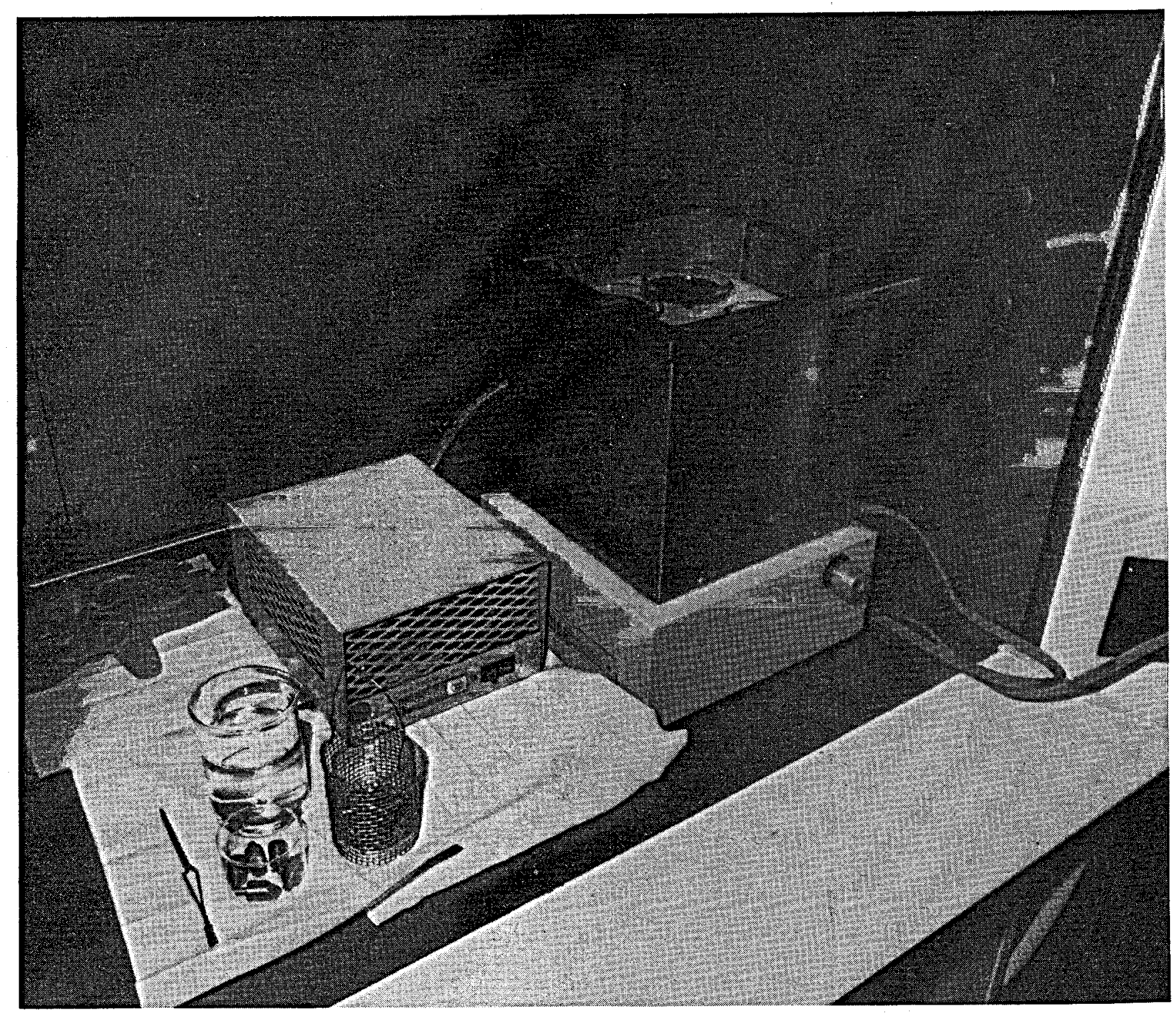

Figure A-1. U1trasonic Cleaner with

Beakers, Wire Baskets,

Studs, and Tongs. (Note

fume hood.) 
4. Slosh rinse in alcohol.

5. Ultrasonic clean in distilled water for 1 to 2 minutes.

6. Slosh rinse in alcohol.

7. Ultrasonic clean in alcohol for 1 to 2 minutes.

8. Blow parts thoroughly dry with dry nitrogen, remove parts from wire basket and store in a clean, covered glass dish in a desiccated dry box. (See Figure A-2.)

If nickel foil is to be used in the bond line, the foil should be at least Grade 200 (99\% pure) and the thickness can be either 0.002 or 0.003 inch. Thin foils can be damaged by the energetic cavitation of ultrasonic cleaners, however, the foils as furnished by metal suppliers are relatively clean. The following steps will result in clean foils for diffusion bond interfaces.

1. Using clean tools and finger cots or gloves, trim strips of foil of a size that can be handled in cleaning containers and foil punch fixtures.

2. Slosh rinse each foil strip, individually, in a container of reagent grade acetone (periodically replace the acetone).

3. Slosh rinse each foil strip in a second container of reagent grade acetone (periodically replace the acetone).

4. Thoroughly blow off excess acetone with dry nitrogen.

5. Punch out foil discs the same diameter as the Stratapax. The punch and die set parts should be cleaned by wiping with trichloroethylene followed by alcohol, or with acetone.

(Note: Many precision punch and die sets contain a plastic insert that strips the foil from the punch. Use only alcohol on plastic parts.)

This insert may leave plastic fibers on the foils unless the insert is modified to prevent this problem. Also, when wipecleaning tooling, lint-free wipes should be used, and the surfaces should be dried using dry nitrogen. 


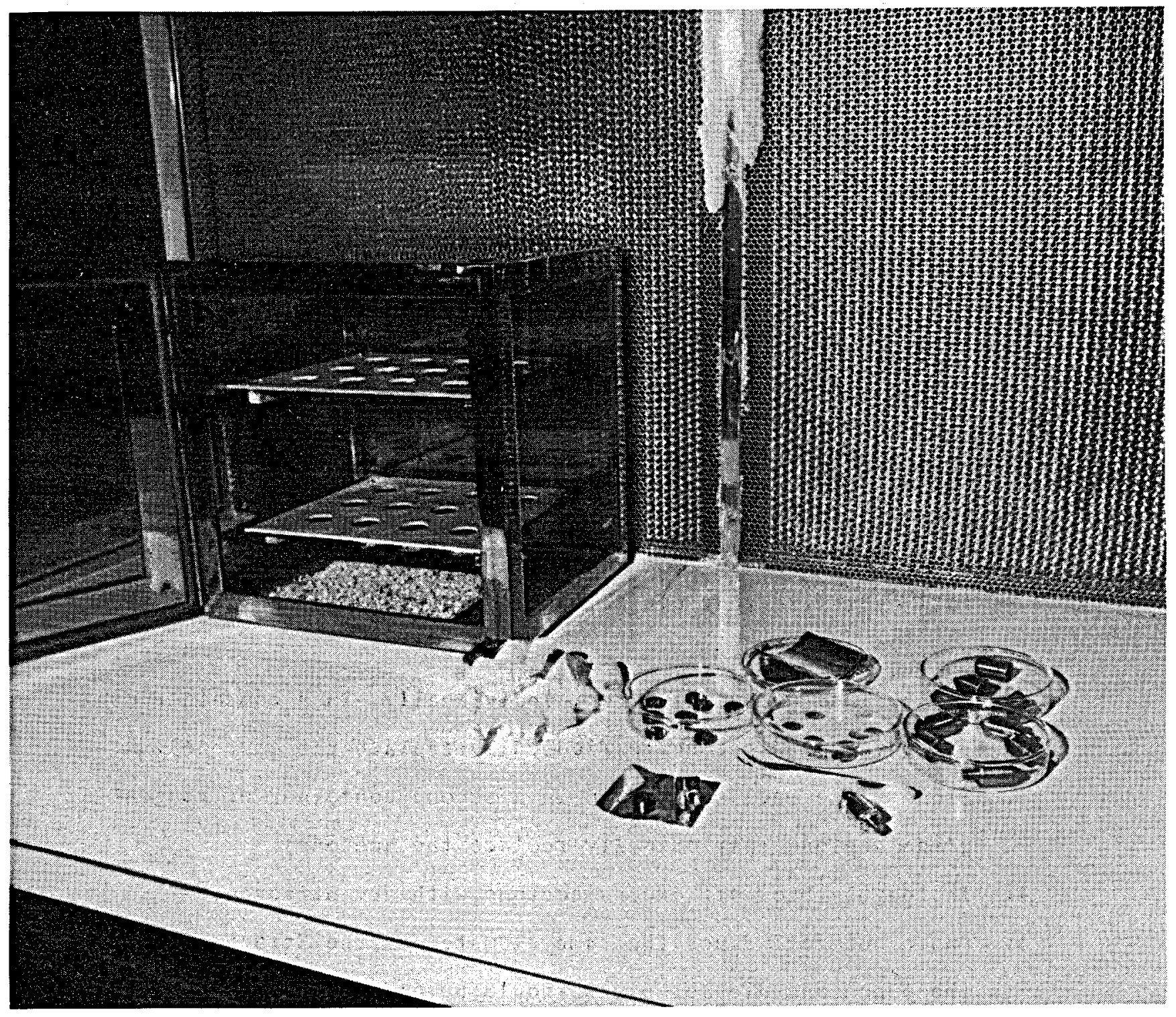

Figure A-2, Clean Bench with Dry Box, Dishes, and Cleaned Parts. 
6. Still using clean tools and/or gloves, place foil discs in clean glass dishes in a desiccated dry box.

The following general rules are helpful in improving the cleaning and reducing the contamination in the ultrasonic equipment.

1. Al1 ultrasonic cleaning should be done under a fume hood which can prevent the escape of vapors into the work area.

2. The ultrasonic cleaner should have a minimum average power density (based on the area of the bottom of the cleaning tank) of 5.0 watts per square inch.

3. The coupling fluid level shall be at the bottom of the overflow opening in the tank when the cleaning beakers are inserted or approximately one inch from the top of the tank if there is no overflow opening.

4. The coupling fluid shall be at a level approximately equal to the liquid level in the cleaning beaker.

5. The coupling fluid shall have approximately $1 / 3 \mathrm{ml}$ of liquid detergent (Joy, Wisk, Ivory, etc.) to each 1iter of water.

6. The ultrasonic cleaner shall be adjusted for maximum plate current after the beakers are placed in the tank if the cleaner does not have automatic tuning provisions.

7. The cleaning beakers shall be glass or stainless steel.

8. Cleaning beakers sha11 be a distance of at 1east $1-1 / 2$ inches from the bottom of the tank and not closer than $1 / 4$ inch from the tank top.

9. Parts being cleaned shall be completely covered with at least one inch of the specified solvent during ultrasonic cleaning and rinsing.

10. No more than one layer of parts should be cleaned per beaker. The volume of parts being cleaned should not exceed one fifth the volume of the solvent being used for that operation. 
11. Parts may touch each other but should be separated so that large plane surfaces are not in direct contact.

12. Parts shall be added to and removed from the cleaning solutions while cavitation is occurring.

13. The cleaning fluids in the beakers should be changed after three or four loads of parts have been cleaned. Discard solution, slosh rinse with sma11 amount of fresh solution of same type, discard the rinse and refill with fresh solution.

14. Hands or gloves which come in contact with the outside of beakers should not come in contact with cleaned parts or wire baskets which fit inside the beakers.

15. Do not drip the coupling fluid from the external surface of a beaker into another beaker or upon cleaned parts.

16. The mesh of the wire used for the parts baskets should be such that there is negligible energy 1oss. For the frequencies used in most ultrasonic cleaners, mesh openings on the order of 0.15 to 0.25 inch are satisfactory.

17. Wire baskets should be either suspended from the top of the beaker or should have a bottom stand-off feature such as shown in Figure $\mathrm{A}-1$.

18. Since oxide formation is critical, do not allow the coupling fluid temperature to increase above $110^{\circ} \mathrm{F}$ (a temperature that is noticeably warm to the touch). This means:

a. Do not subscribe to a common practice of extended precleaning warm-up times--30 seconds will suffice.

b. Do not use excessive ultrasonic cleaning time in each step. These parts do not have dirt-trapping internal surfaces, so 1 to 2 minutes per step is enough.

c. If a large number of parts are to be cleaned, plan on periodic shutdowns to change the coupling fluid in the tank. 
19. Do not allow parts to dry between u1trasonic cleaning steps. If parts are allowed to dry between cleaning steps the contamination in solution of the last step will remain on the part when the volatile cleaning solution evaporates, and if the subsequent chemicals are not capable of redissolving that contaminant, it will remain on the part.

20. Use wire baskets to hold parts for all cleaning steps. Fishing parts in and out of beakers with tweezers or other tools is time consuming, risks dropping parts, and causes increased worker inhalation of toxic vapors.

21. Once a group of parts is placed in a wire basket, they stay there for the entire cleaning process. When this wire basket of parts is removed from a beaker of a solution, hold the basket of parts directly above this beaker until the majority of excess solution has dripped off. (Sharp, short vertical motions accelerate this step.)

22. Contamination buildup in ultrasonic cleaning solutions can be minimized by using "slosh rinses" in between ultrasonic cleaning steps. The slosh rinse beakers are alongside the ultrasonic cleaner. The rinse is accomplished by rapidly moving the wire basket of parts into and out of the beaker four or five times.

23. A common error in ultrasonic cleaning is the mixup of solutions and/or skipping a cleaning step. The ultrasonic cleaning and slosh rinse beakers should be numbered in the sequence of the steps.

24. Maintain all beakers, wire baskets, handling tools and part storage containers in clean condition using the following steps:
a. Wash utensils in liquid detergent and hot water.
b. Rinse cleaned utensils under hot running water. 
c. Agitate rinsed utensils in a stainless steel pan of alcohol, rinsing entire surface of utensil.

d. Allow alcohol to evaporate or blow dry with dry nitrogen and place upside down on a clean surface. 
APPENDIX B

\section{HOT ISOSTATIC PRESSING}

\section{GENERAL}

The diffusion bonding is accomplished by simultaneous application of high pressure and high temperature. The process used by Sandia is more specifically called gas pressure diffusion bonding, or hot isostatic pressing (HIP). The high pressure that is used $(30,000 \mathrm{psi})$ requires equipment that is found only in laboratories that specialize in HIP.

In the diffusion bonding process, the parts to be welded must be hermetically sealed in a container to exclude the gas from the diffusion bond interface. The sealed container must be deformable at the processing temperature, and either the container walls and/or an intermediate material must transmit the autoclave gas pressure to the parts to be diffusion bonded. This appendix provides the container preparations and the autoclave variables used by Sandia in the HIP of drill bit cutter assemb1ies.

\section{HIP PREPARATIONS}

Sandia Labs has experimented with several types of HIP containers and pressure transfer mediums. The only combination that will be detailed in this report is the one that was used most often and had the best success. The process summary for HIP preparation is given in the main text of this report, and this appendix is intended to provide enough detail to enable process duplication by others.

\section{Preparation of Cutter Assemblies}

These steps must be performed in a clean environment. At Sandia, we used a laminar flow clean bench. The cleaned Stratapax, studs and bond line foils are stored in a desiccated dry box and the dry box was 
kept in the clean bench (see Figure A-2).

The cermet surface of the Stratapax is placed against the surface of the stud, with or without the bond line foil, and the assembly is wrapped in 2.5 inch square oxygen-free copper foil. The person wrapping the assembly should wear finger cots or gloves. The copper foil thickness is not critical, but Sandia found that 0.001 inch thick foil could be wrapped tightly with low tear probability. The copper foil serves two purposes: (1) positions and holds the Stratapax on the surface of the stud, and (2) provides a seal to exclude the graphite from the bond line. Figures $B-1$ and $B-2$ show various stages of the wrapping process.

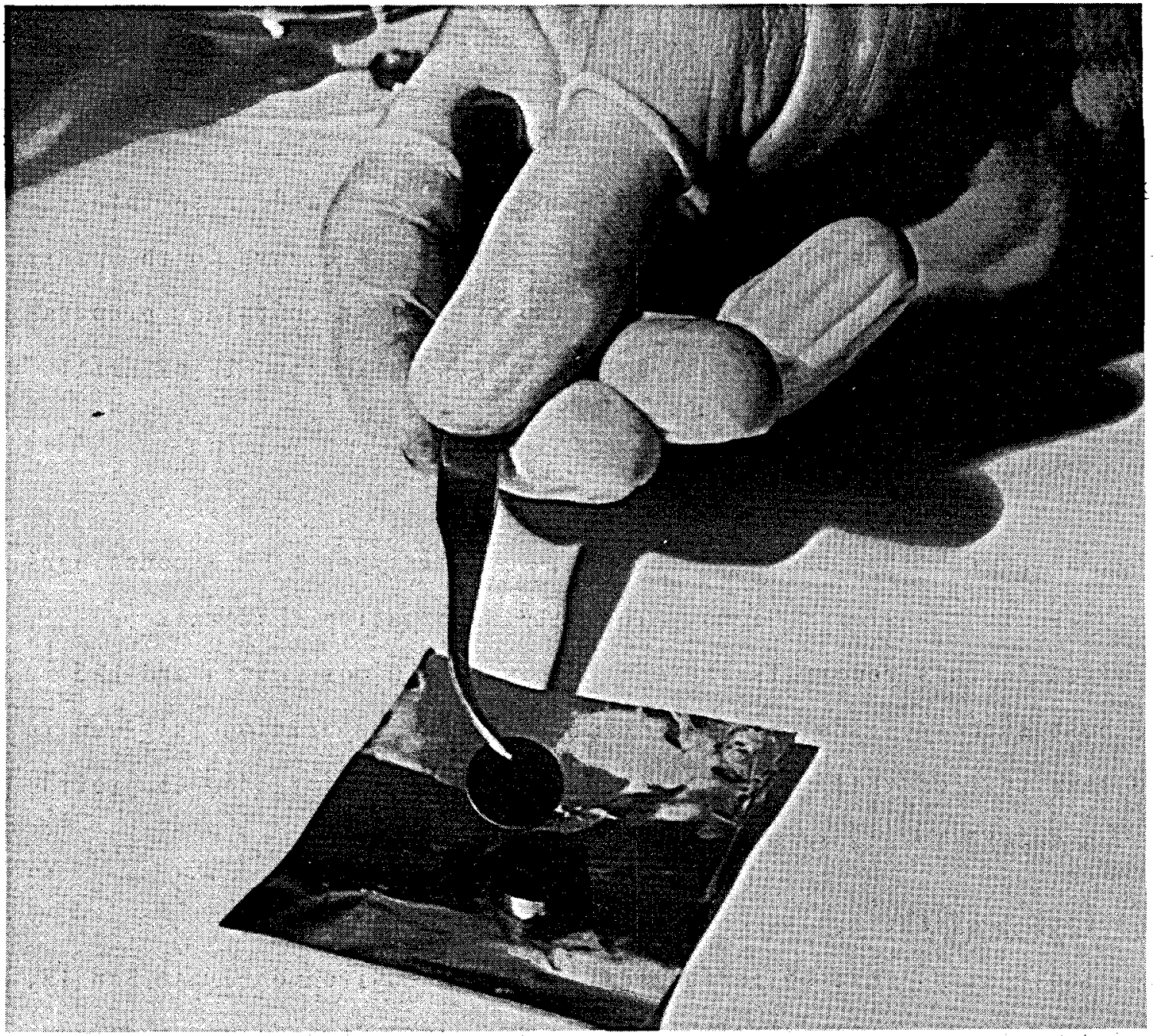

Figure B-1 (a). Placing the Bond Line Foil on the Stratapax 


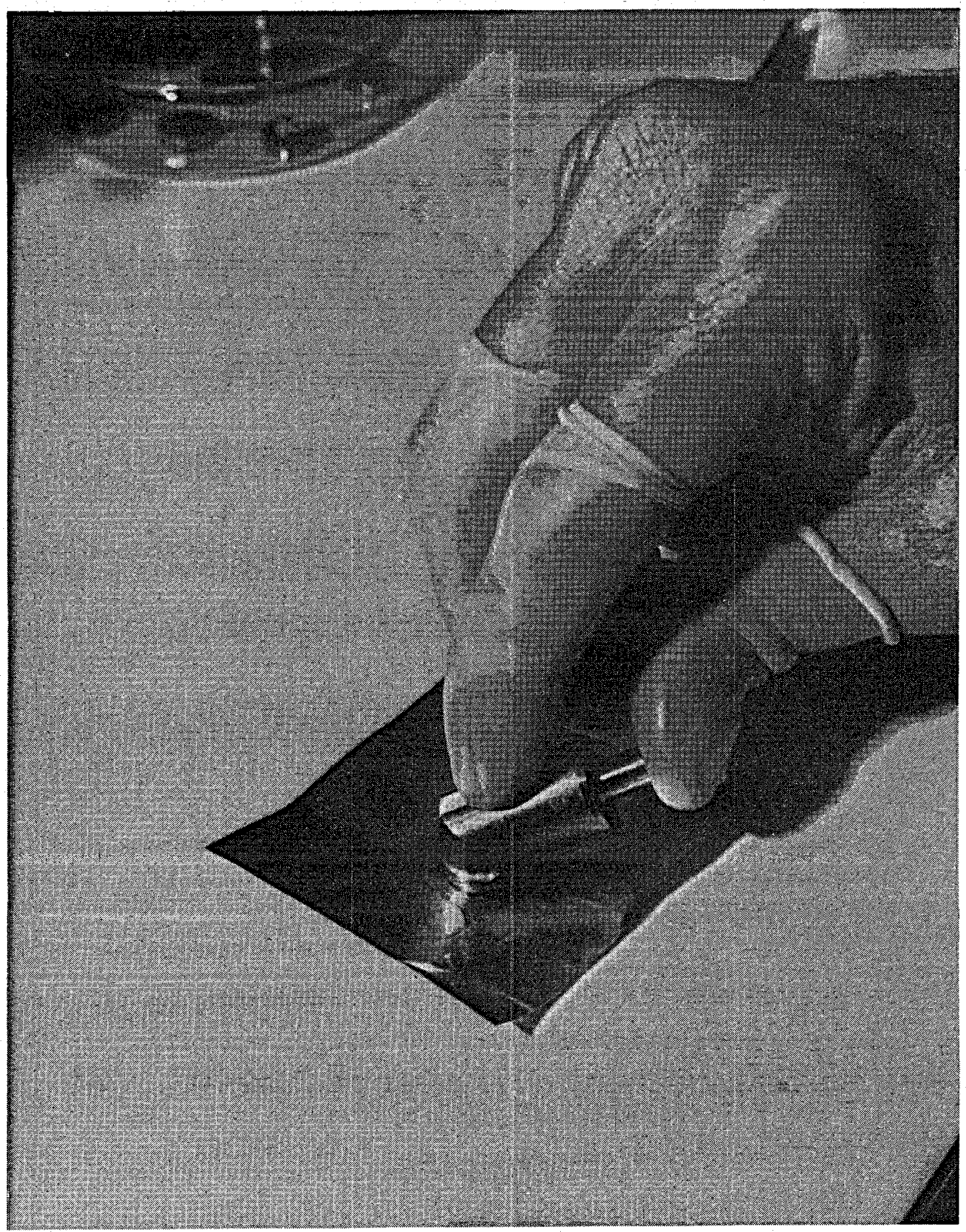

Figure B-1 (b). Holding the Stud Against the Foil/ Stratapax Stack. 


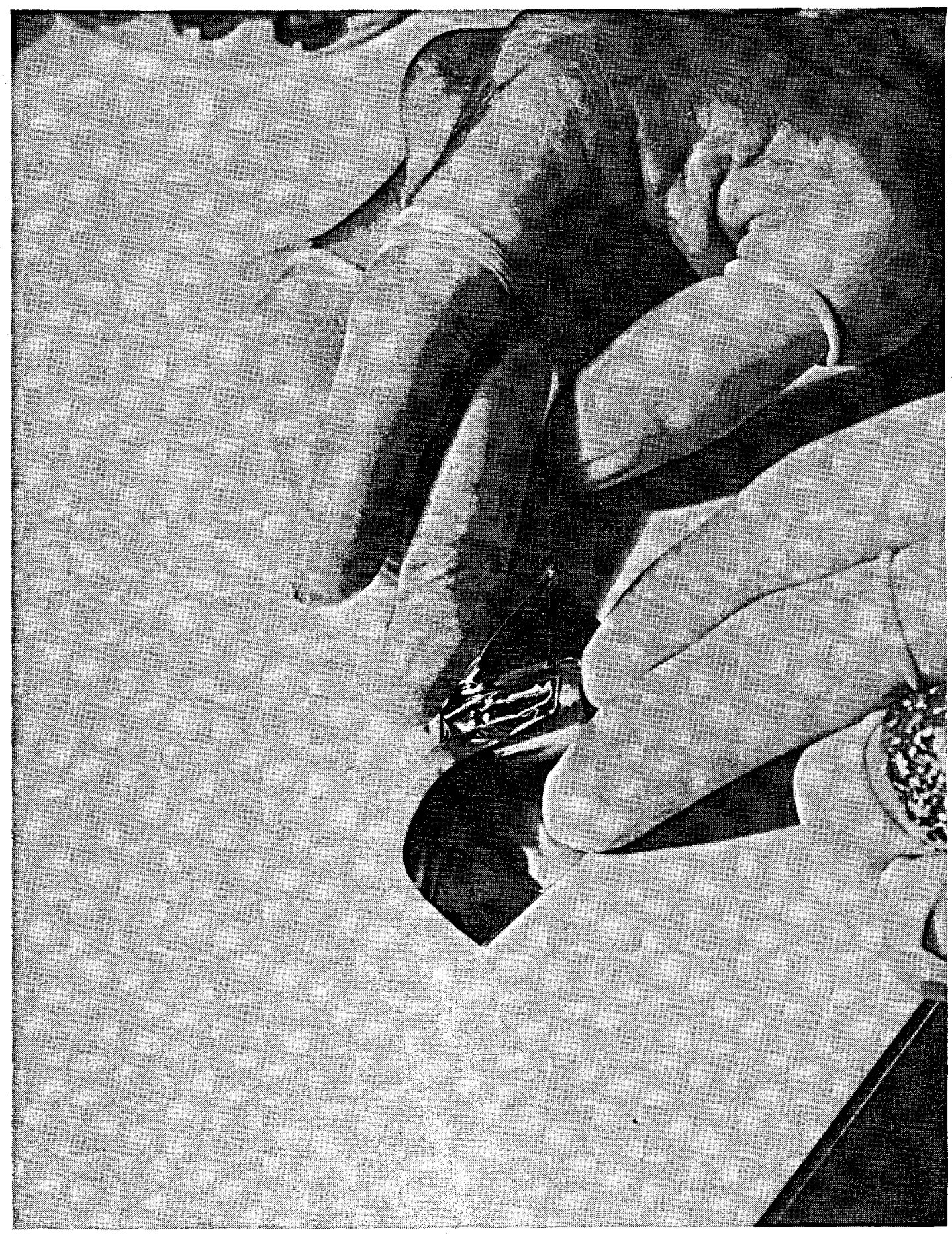

Figure B-2 (a). Beginning to Wrap the Copper Foil Around the Cutter Assembly. 


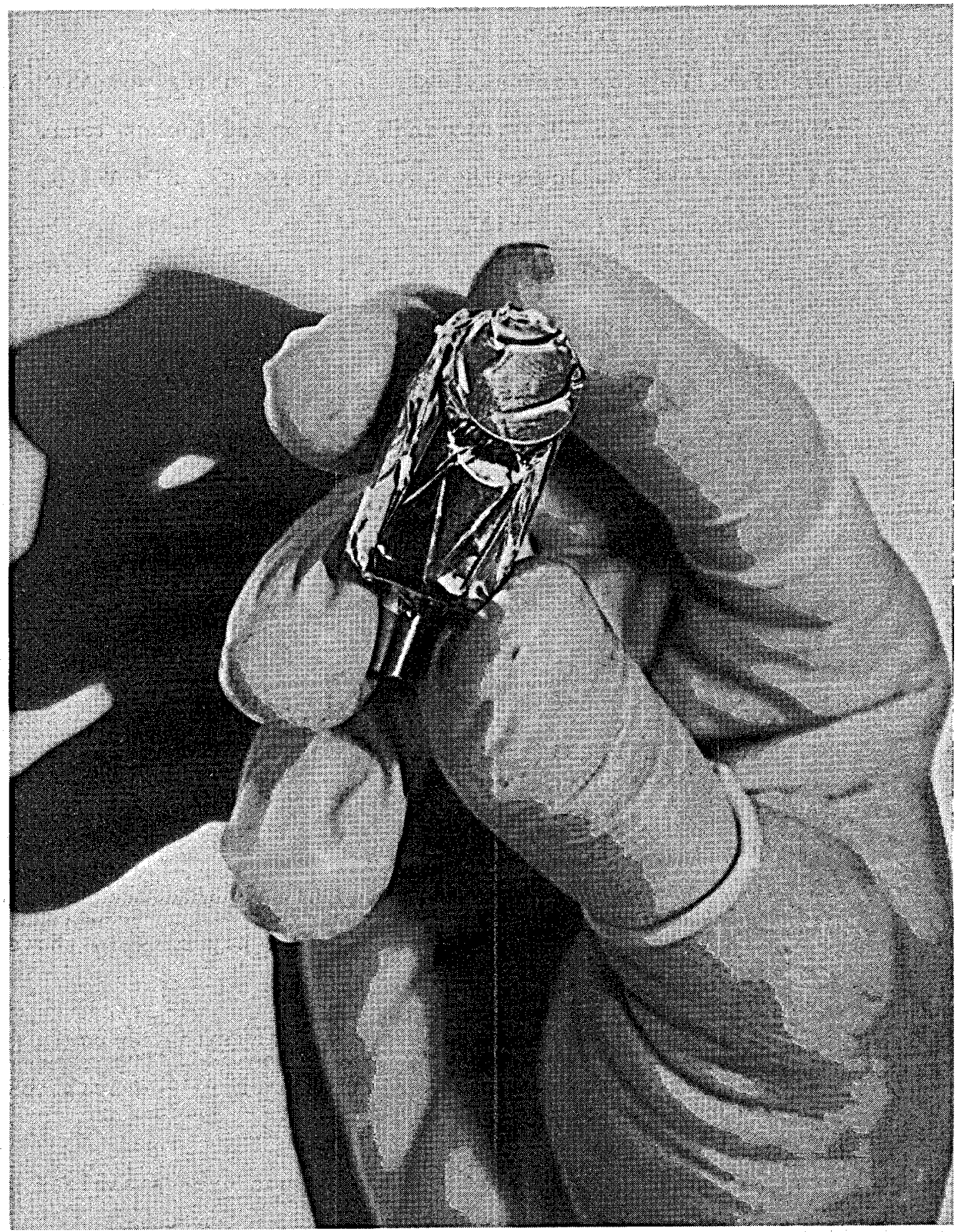

Figure B-2 (b). Complete Wrapped Assemb1y. 


\section{Preparation of the HIP Containers}

The following materials were used for the Sandia HIP containers (see Figure B-3 for photograph of actual parts):

1. Cans of killed low carbon steel, seamless tubing per ASTM-A519, grade 1015,1 inch oD $x .035$ inch wall $x 9.5$ inches long.

2. End caps of killed low carbon steel sheet per ASTM-A-515, grade $1015, .035$ inch thick.

a. Caps are formed into cup to be a light press fit into the cans. Cap cup is $3 / 8$ inch long with $1 / 8$ inch interior corner radius.

b. One cap has $15 / 64$ reamed hole for evacuation tube.

3. Evacuation Tubes

a. Stress relieved and annealed stainless steel tubing per ASTM-A-213, grade TP304L, .25 inch OD $x .030$ inch wa11 $x$ 3.5 inch long. Machine one end for a press fit into an end cap.

b. Oxygen-free copper tubing per ASTM-B-75, UNS No. 10100, .25 inch OD $\times .035$ inch wa11 $\times 3$ inches 1ong. Swage one end to fit over steel tube for approximately $1 / 4$ inch overlap.

The can parts should be deburred, thoroughly vapor degreased, and kept in clean, desiccated storage. Partially assembly cans in these steps.

1. GTA (Gas Tungsten Arc) weld the bottom cap into the can.

2. Helium leak test this weld (requires commercial He leak test equipment).

3. Vacuum furnace braze swaged end of Cu tube over stainless stee1 tube.

4. GTA weld stainless steel tube into end cap.

5. He leak test top cap and evacuation tube assembly.

6. Store container parts in clean, dry storage. 


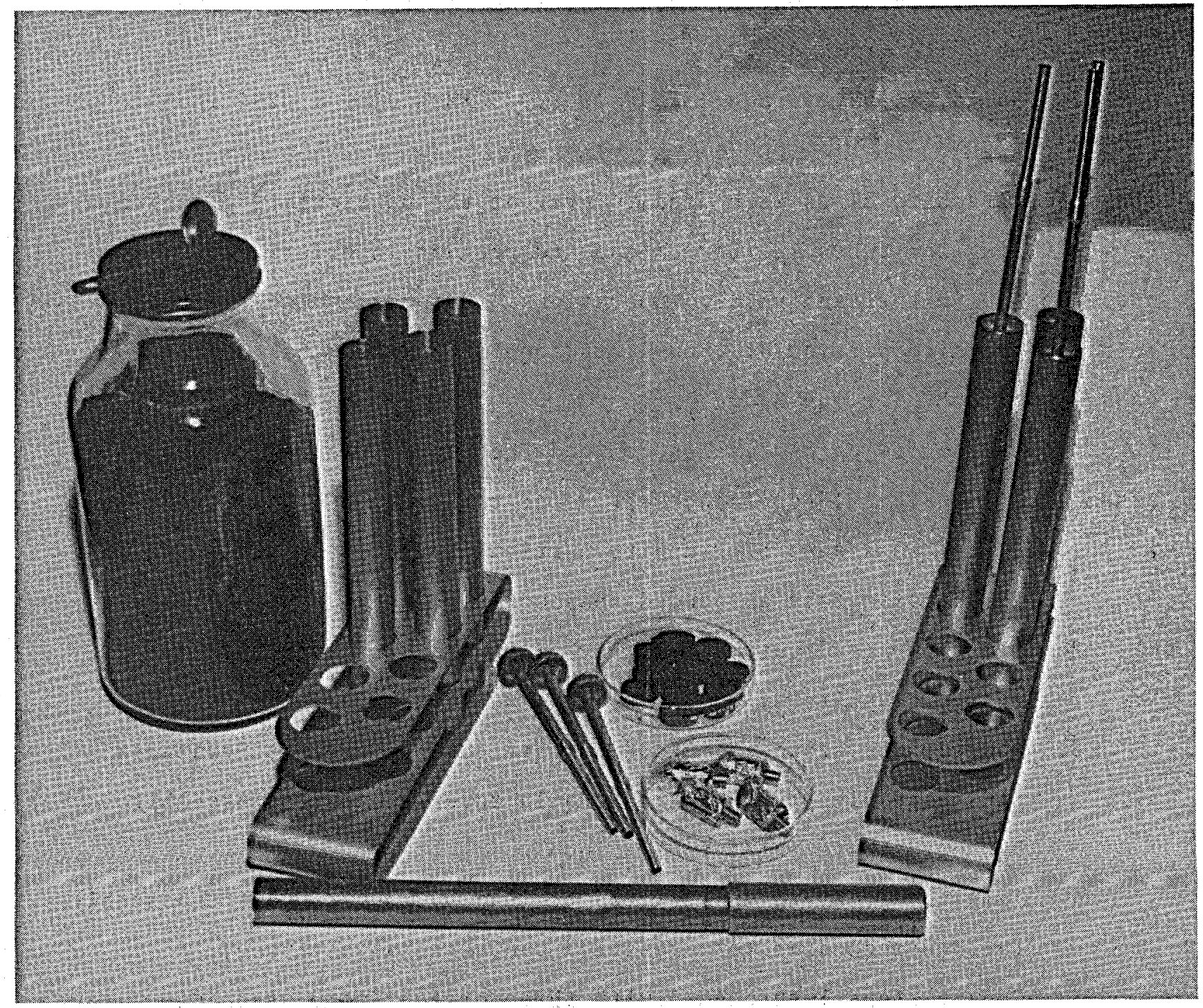

Figure B-3. Parts Required for HIP Assemb1y. Clockwise from bottom: Tamping Rod; Jar of Granulated Graphite, Cans in Stand, End Caps with Evacuation Tubes, Graphite Discs, Wrapped Cutter Assemb1ies, Assembled but Unsealed Cans. 


\section{Loading HIP Containers}

Before starting this step, the graphite pressure transfer medium must be prepared. The graphites used by Sandia were:

1. Particulate graphite, mesh size minus 12 to plus 28 , Poco Graphite grade RP-5Q.

2. Solid graphite grade ECV discs (.925 inch dia. $x .250$ inch high).

The solid graphite discs were used to prevent the particulate graphite from entering the tubes in the top cap and perhaps interfering with subsequent pinch-off and welding operations. Before loading the cans, both the graphite particulate and discs should be vacuum baked coutgassed) at $900^{\circ} \mathrm{C}$ for one hour.

Use the following procedures to load the copper wrapped cutter assemblies into the HIP containers. (Refer to Figure B-4):

1. Place two scoops of graphite particulate into the can (a scoop is approximately a rounded teaspoonful).

2. Drop a wrapped cutter assembly (with the Stratapax up) on top of the graphite.

3. Place three scoops of graphite particulate over the Stratapaxstud assembly (the graphite should cover the cutter assembly by approximate1y $1 / 4$ to $1 / 2$ inch).

4. Tamp the grahpite until it is closely packed around the assembly (a .900 inch diameter brass rod can serve as a tamper).

5. Repeat steps 1 through 4 with three or four more wrapped assemblies. Reverse the Stratapax-stud assembly orientation for the last two (i.e., place the wrapped assembly in the tube with the Stratapax downwards).

6. Fill the can with graphite particulate so the tamped level is approximately $3 / 4$ inch from the top of the can.

7. Insert a solid graphite disc over the particulate. The top of 
the disc. should be about $1 / 2$ inch below the top of the can.

8. Force an evacuation tube and end cap assembly into the can until the edge of the end cap is flush with the can.

NOTE: From this point on, it is important that the filled HIP containers remain in the upright position until the final welding of the stainless steel evacuation tube at the end of this section. Note the use of laboratory test tube stands in Figure $B-3$.

9. GTA weld the end cap into the tube. Heat sink the can during welding to prevent oxidation of the cutter assemblies.

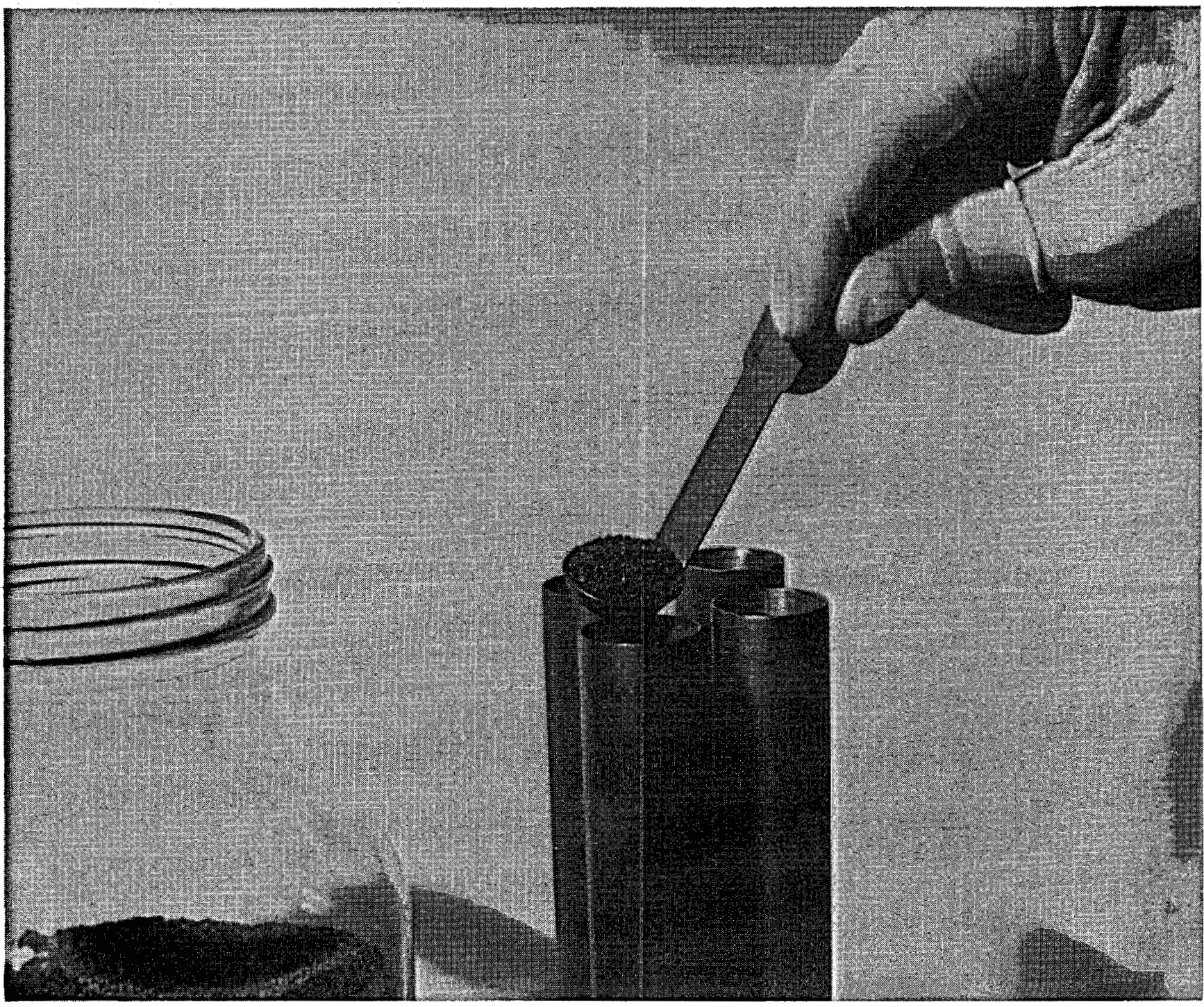

Figure B-4 (a). Scoop Granulated Graphite into Can. 


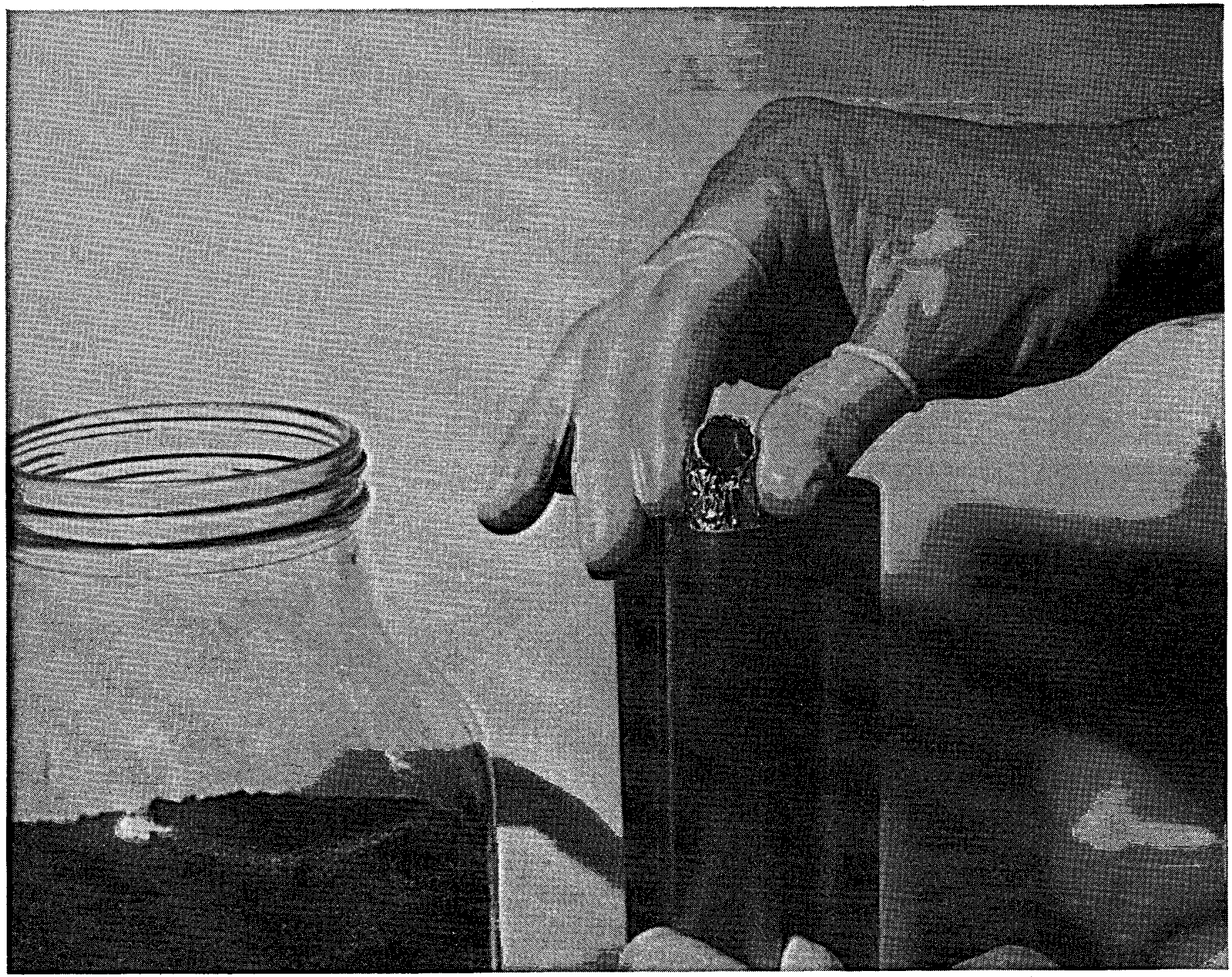

Figure B-4 (b). Drop Wrapped Cutter Assembly into Can. 


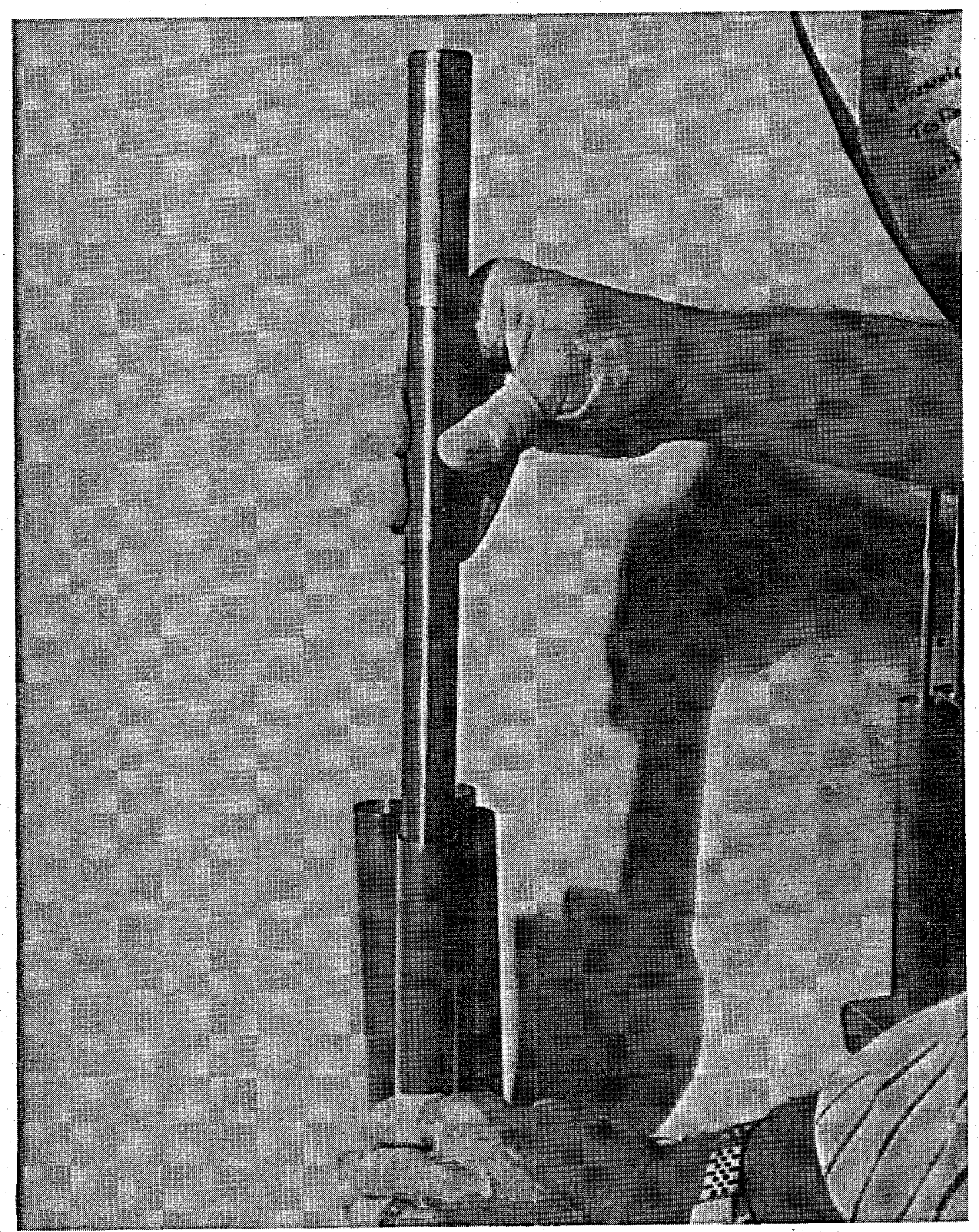

Figure B-4 (c). Tamp Graphite After Each Cutter Assembly. 


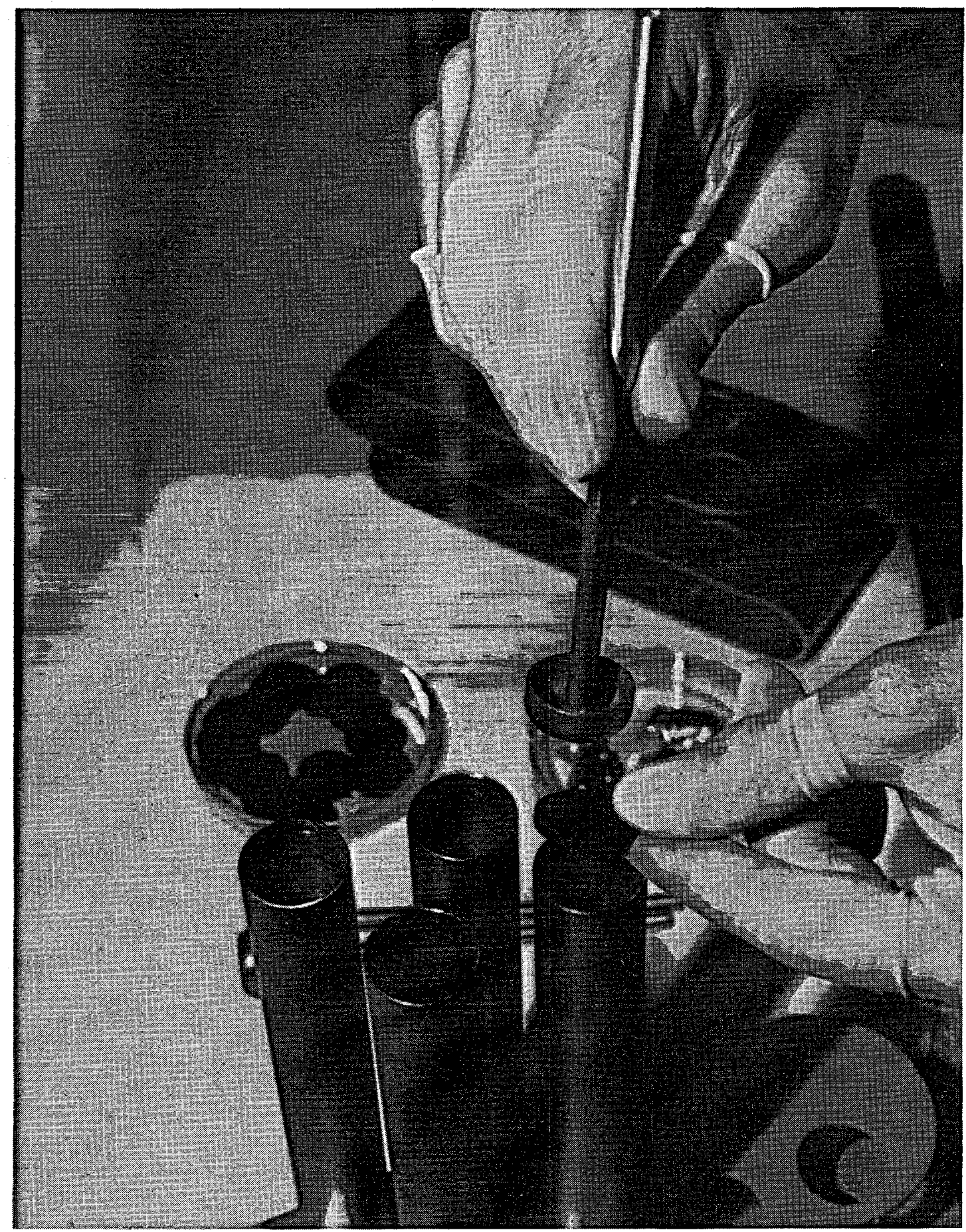

Figure B-4 (d). P1ace Graphite Disc and End Cap in Tube After Last Cutter Assemb1y. 
Evacuating and Sealing the HIP Containers

Connect the loaded cans to a vacuum system. Sandia used a turbo molecular pump and a 12-can capacity rigid manifold with 0 -ring fittings sealing around the copper pinch-off tube (see Figure B-5). The turbo pump is better than necessary, but the vacuum system should be able to reach at least $5 \times 10^{-6} \mathrm{~mm} \mathrm{Hg}$, and preferably $1 \times 10^{-6} \mathrm{~mm} \mathrm{Hg}$. Back streaming of vacuum pump oil must be avoided.

Evacuate the tubes for a minimum of 4 hours with a manifold pressure of less than $5 \times 10^{-6} \mathrm{~mm} \mathrm{Hg}$. The low diffusion rates of air through the copper wrapping, through the graphite and out the small evacuation tubes require a rather lengthy time at vacuum. After 4 hours and after the manifold pressure is less than $5 \times 10^{-6} \mathrm{~mm} \mathrm{Hg}$, apply a temperature of 100 to $125^{\circ} \mathrm{C}$ to the cans. Sandia used a 750 watt heat tape interlaced around the cans and an insulating glass fiber blanket. Continue the vacuum as the heat is applied for two hours. The outgassing will increase the manifold pressure. Remove the heat but maintain the vacuum. After the cans have cooled nearly to room temperature, the cans are ready for the final sealing processes.

Pinch-off sealing of the copper tubes allows one to remove the cans from the vacuum pump without losing the vacuum in the cans. However, the sealed copper tube cannot withstand the HIP temperature and pressure, so the copper tube pinch-off must be followed by sealing the stainless steel evacuation tubes. The tube sealing is critical and methods for sealing both the copper and steel tubes should be perfected by process experimentation using trial pieces of tubes.

The pinch-off of the copper tube is relatively straightforward, thanks to the availability of commercial pinch-off tools. Pinch off the copper tube while the manifold is under vacuum. 


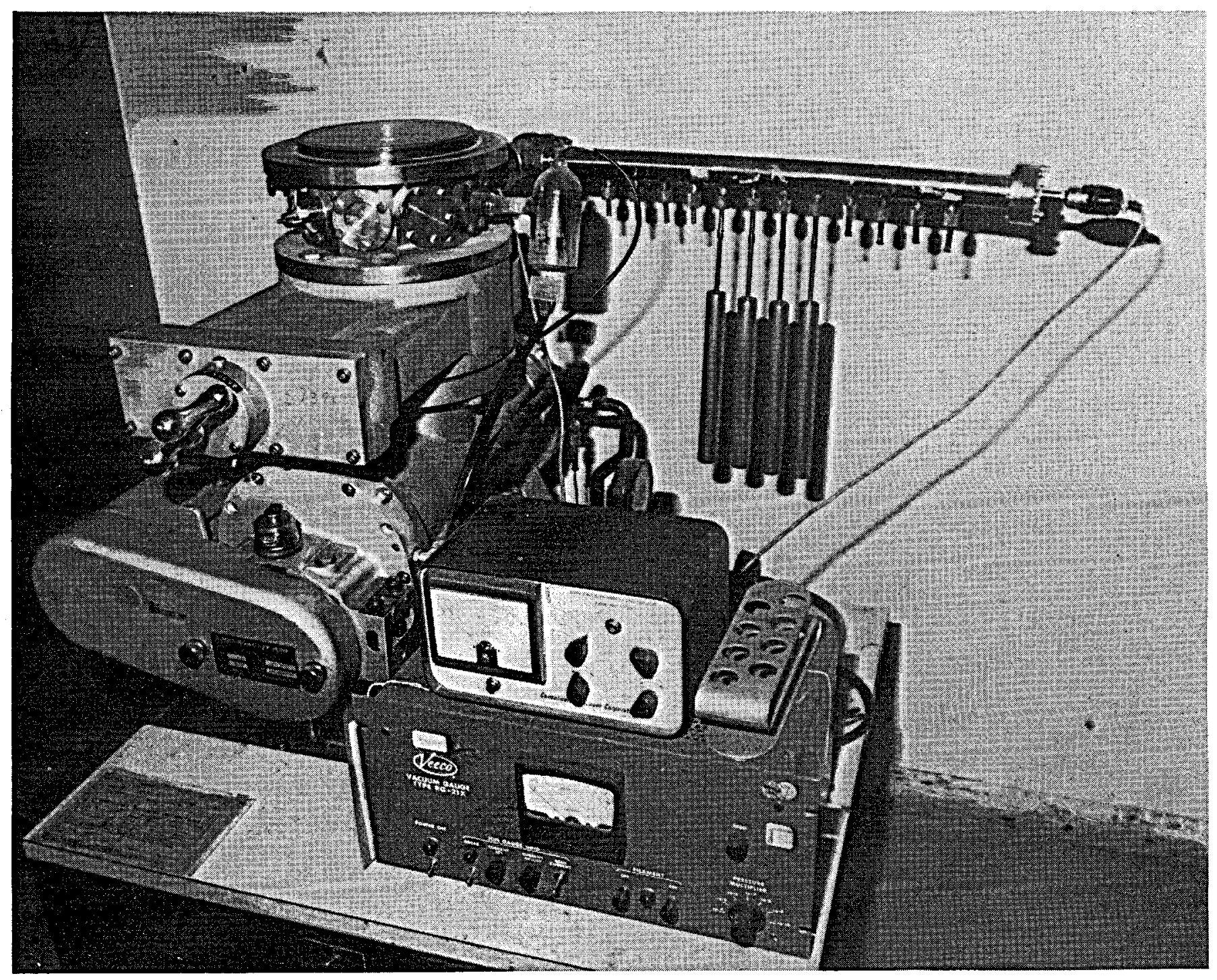

Figure B-5 (a). Vacuum Pump and Manifold 


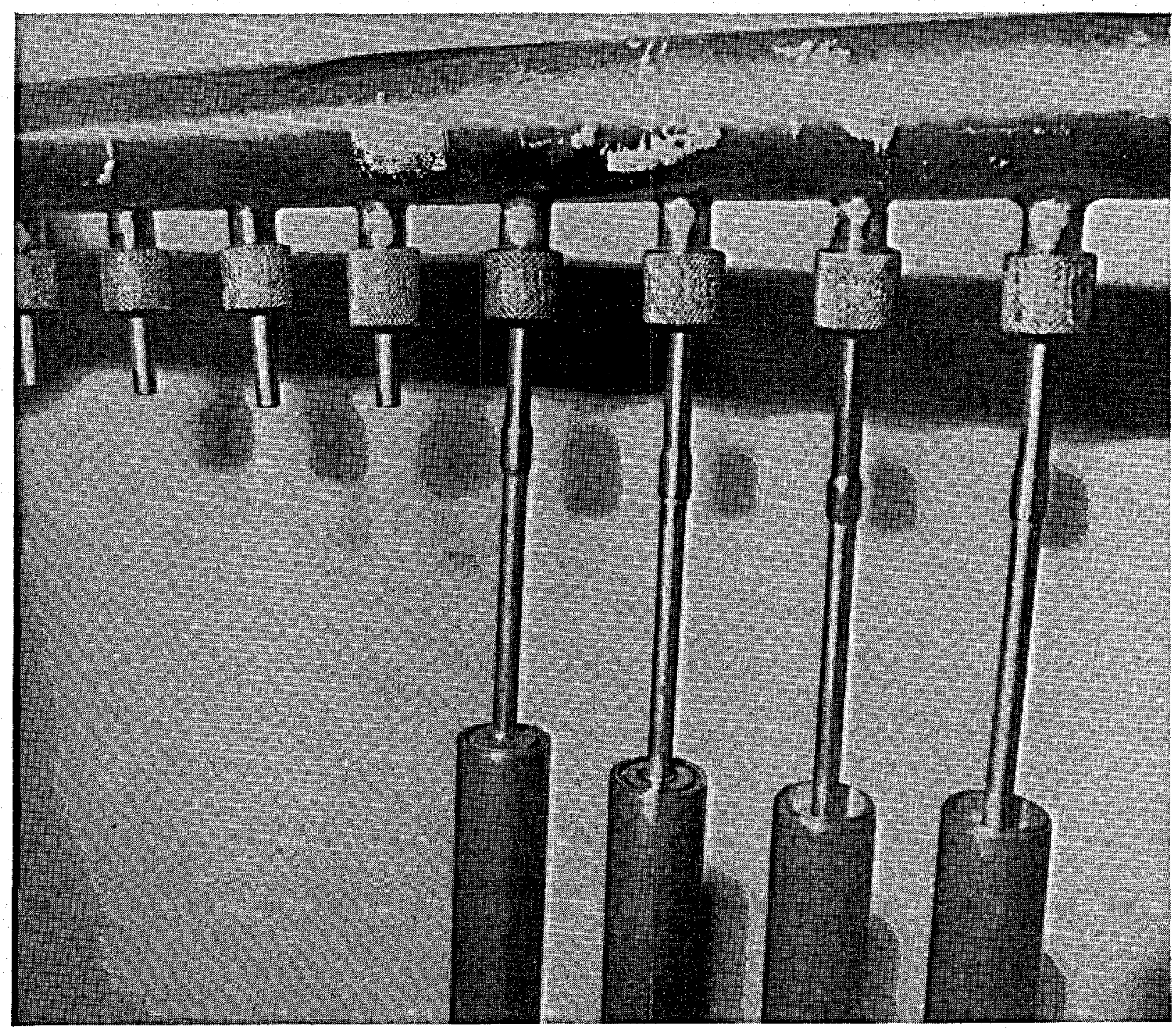

Figure $B-5$ (b). Manifold Fittings

(solid rods in unused ports) 
For sealing the stainless steel tube, Sandia used a resistance welder that simultaneously applied high pressure and electrical current (heat) and used chisel welder tips with a $1 / 8$ inch tip radius. (See Figure B-6.) However, a commercial drill bit manufacturer has successfully developed a procedure where a torch is used to locally heat a spot on the steel tube and while still red hot, a large pair of modified bolt cutters makes the tube closure sea1. The bolt cutters are modified by grinding the sharp jaws into radii.

Once the steel evacuation tube is sealed, the cans are ready to be subjected to the HIP. The Sandia tubes were always pre-HIP leak tested, but this step is certainly optional if one is willing to take the risk of losing some cutter assemblies. Prior to leak testing the tubes, we cut off the copper tube to enable leak testing of the pinched off stee 1 tube. (Remember that the copper tube cannot survive HIP but can mask a leaking steel tube pinch-off in the pre-HIP leak test.) The leak testing of a sealed container such as these cans is accomplished by bombarding the exteriors of a group of cans with one atmosphere of He for at least 6 hours, then checking each can for He leaking back out. From Sandia's experience, leak rates less than $1 \times 10^{-7} \mathrm{cc} / \mathrm{sec}$ resulted in acceptable HIP behavior (i.e., the amount of air that could leak in before the. cans could be subjected to HIP did not significantly degrade the quality of the diffusion bond.)

\section{HIP PROCESS VARIABLES}

The HIP for the majority of Sandia's drill bit cutter assemblies was by Industrial Materials Technology, Inc. (IMT) in Andover, Mass. The HIP cycle consisted of pressurizing to 30,000 psi for 6 hours at $675^{\circ} \mathrm{C}$. At this pressure, IMT had an autoclave that could accommodate approximately 20 cans of the design previously described.

The 30,000 psi is perhaps a 1ittle higher than required, but the next size larger autoclaves are rated at a margina1 15,000 psi. The 


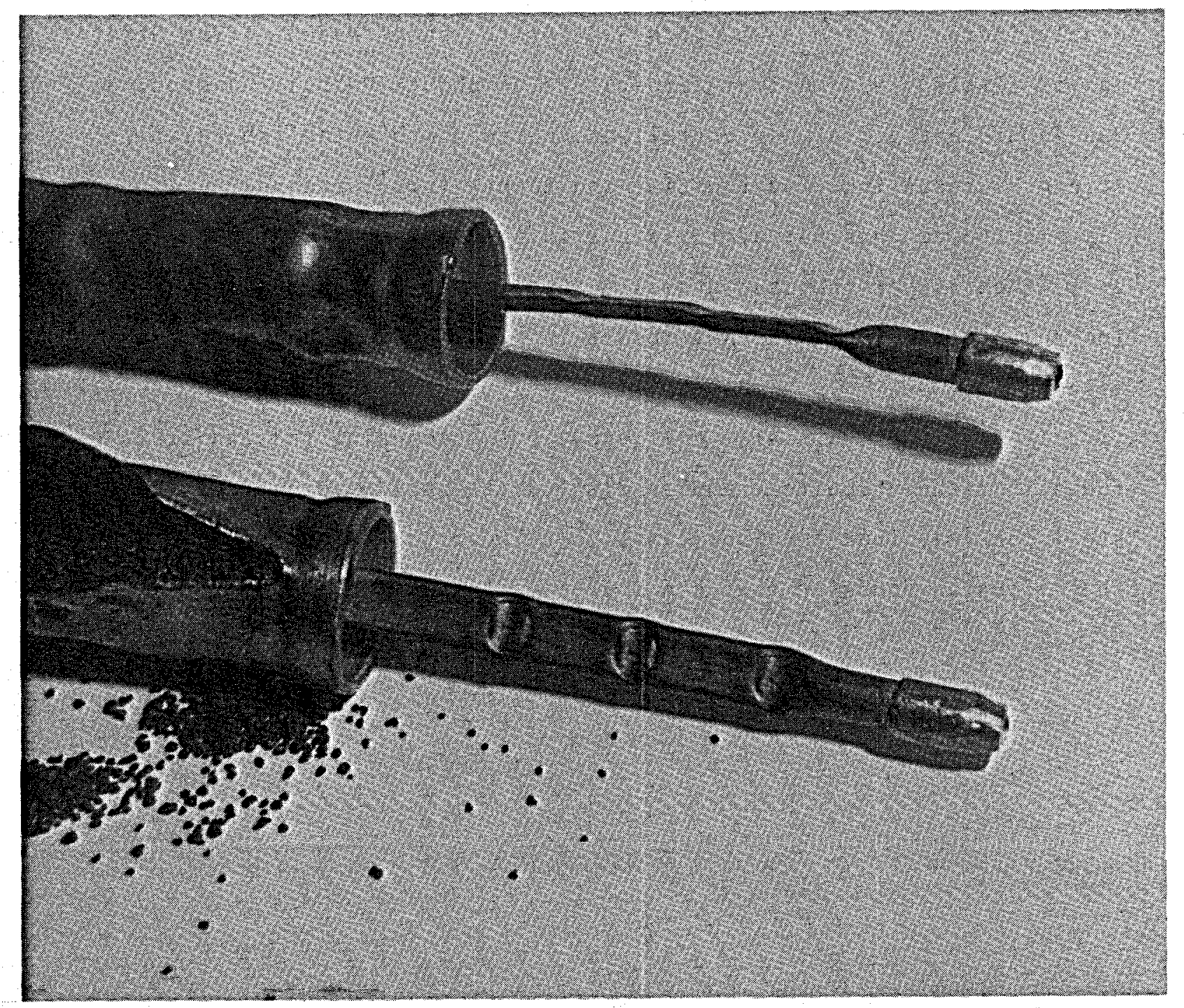

Figure B-6. Stainless Stee1 Evacuation Tube with Resistance Welded Seal. 
HIP time was increased from 4 hours to 6 hours for the most recent groups of Sandia cutter assemblies. The 4 hours was adequate, but it was felt that the sma11 additional cost for 2 more hours might buy a significant increase in bond strength. Also the temperature was recently increased from $650^{\circ} \mathrm{C}$ to $675^{\circ} \mathrm{C}$ for the same reason. (The Stratapax is limited to a maximum temperature of about $700^{\circ} \mathrm{C}$.) However, Sandia did not perform a controlled experiment to establish relative strengths resulting from the time and temperature increases.

If the can has not at least partially collapsed after HIP (Figure B-7), then either the can material or weld material failed and gas leaked into the can. The net result is no diffusion bond of the cutter assemblies.

If a can has partially collapsed, but on opening the can it is found that the graphite granules dimpled the inside surface of the steel can less than on other cans, then there was a smaller leak and the diffusion bonds in that can may be of inferior strength. 


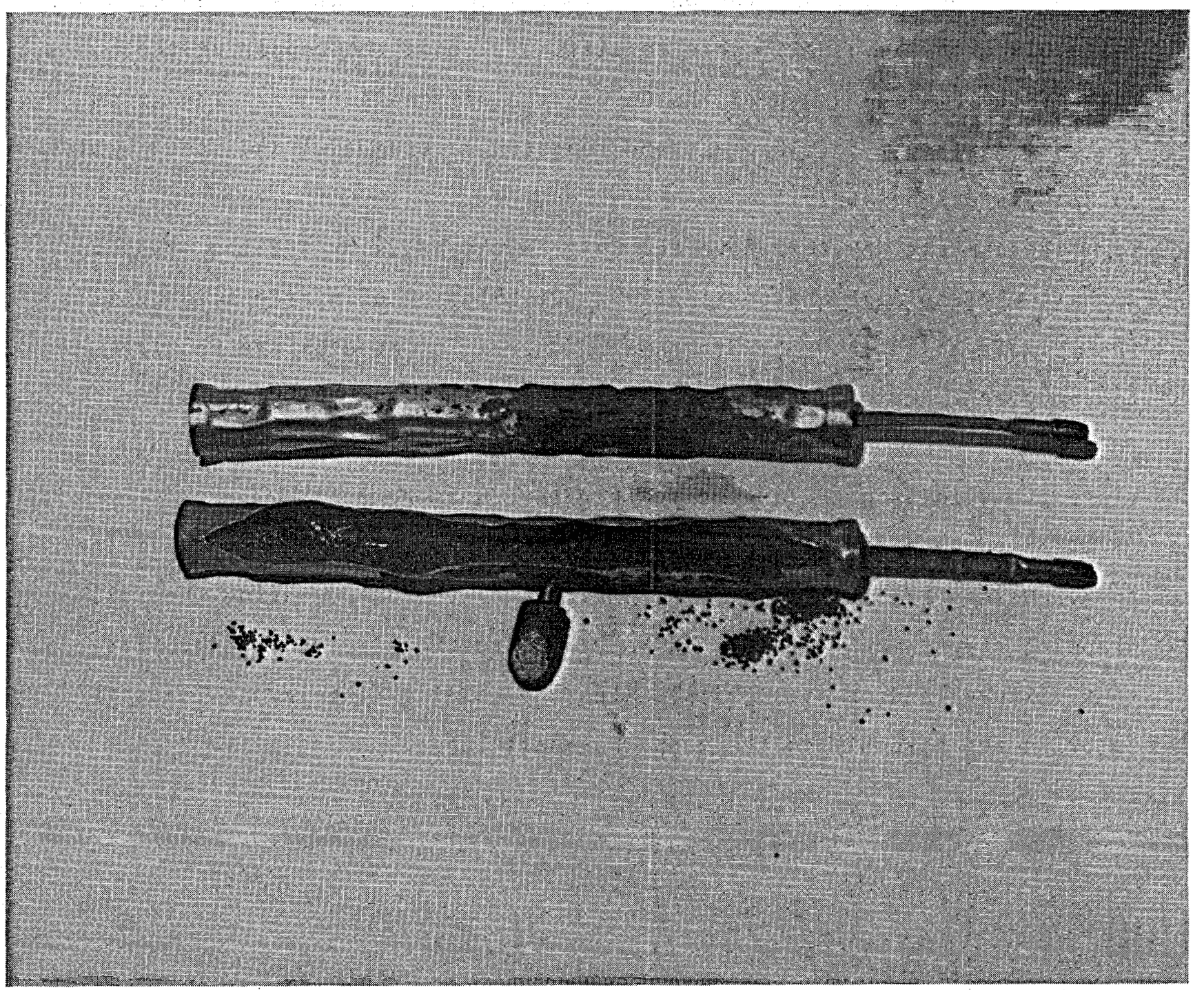

Figure B-7. Collapsed Post-HIP Can (top) and Opened Can with Bonded Cutter Assemblies. 


\section{CUTTER ASSEMBLY CLEANUP}

After cutting open the cans and removing the cutter assemblies, the assemblies must be cleaned up for subsequent testing and/or installation in a bit. The copper adheres only slightly to the Stratapax, and with a knife blade one is usually able to lift an edge of the copper at the edge of the diamond and pee1 the $\mathrm{Cu}$ off the diamond surface. The studs are more difficult to clean and the tungsten carbide (WC) and steel will be discussed separately.

The easiest way to remove the $\mathrm{Cu}$ from the WC is by setting studs in a shallow glass dish and pouring in a $50 \%$ solution of nitric acid until the acid is just below the Stratapax. Only a few minutes are required to remove the $\mathrm{Cu}$. Since the nitric acid can etch out the Ni bondline foil, be careful to keep the acid below the Stratapax and to thoroughly rinse the acid from the assembly after the $\mathrm{Cu}$ is removed.

The easiest way to remove the $\mathrm{Cu}$ from the steel studs is to machine them. Using the bottom tang, which was kept free of $\mathrm{Cu}$ during the foil wrapping steps, machine the stud body dwon to the size required to fit test fixtures and/or drill bits. Then the holding tang is machined off to bring the assembly to the proper overall length. 


\section{APPENDIX C}

\section{TESTING}

GENERAL

During the development of the diffusion bonding process, a significant effort was spent on both non-destructive and destructive test methods. The non-destructive methods were ultrasonic testing and subfailure shear testing. The destructive test employed by Sandia was to take a diffusion bonded assembly to its ultimate shear load. This appendix discusses both kinds of testing and provides information on test procedures, equipment design and results. The diffusion bond strengths were found to be nearly identical for both steel and WC studs.

\section{NON-DESTRUCTIVE TESTING}

\section{U1trasonic Testing}

Ultrasonic testing is a powerful tool in determining the quality of diffusion bonded assemblies. After development of the ultrasonic test equipment and procedures, Sandia used them on $100 \%$ of the diffusion bonded assemb1ies. However, although there are many things you can do with ultrasonics, there are certain limitations:

1. The resolution of bond line defects is controlled by the size of the transducer (i.e., don't expect to find $1 / 8$ inch diameter defects in a bond line if the ultrasonic transducer is $1 / 2$ inch in diameter).

2. U1trasonics can te11 whether or not a bond exists between two surfaces, but if a bond does exist, ultrasonics cannot determine whether it's a strong bond or a weak bond (e.g., ultrasonics may show that a Stratapax-stud bond exists, but either or both parts could have a heavily oxidized surface resulting in an extremely weak bond). As a result of the limitations, ultrasonics must be used in conjunction with actual bond strength testing. 
Figure $\mathrm{C}-1$ shows an ultrasonic test setup, and Figure $\mathrm{C}-2$ is the schematic of the pulser/receiver. There are also commercial pulserreceivers available. The following detailed procedure assumes the Sandia-designed pulser/receiver and may require slight modifications in setup if a commercial unit is used. However, the analysis of the data will be the same in all cases.

1. Equipment Required
a. Oscilloscope and cables
b. Pulser/receiver
c. $10 \mathrm{MHz}$ transducer and matching cable
d. U1trasonic couplant fluid (or gel)

2. Oscilloscope Setup
a. Set gain to .1 volt per division
b. Set sweep rate to 0.5 microsecond per division
c. Set trigger source to external
d. Set trigger mode to auto

3. Oscilloscope-Pulser/Receiver $(P / R)$ Connections
a. $P / R$ output cable to scope input
b. $P / R$ trigger (sync) cable to scope trigger input

4. Test Procedure
a. Clean diamond face including any remaining copper
b. Dip transducer face into ultrasonic couplant
c. S1ide transducer surface against diamond surface with sufficient finger pressure to establish good coupling (as indicated by maximum vertical reading on scope).
d. Slide transducer around diamond surface to scan for unbonded areas. If reflections decrease, coupling may have to be re-established by repeating $b$ and $c$.




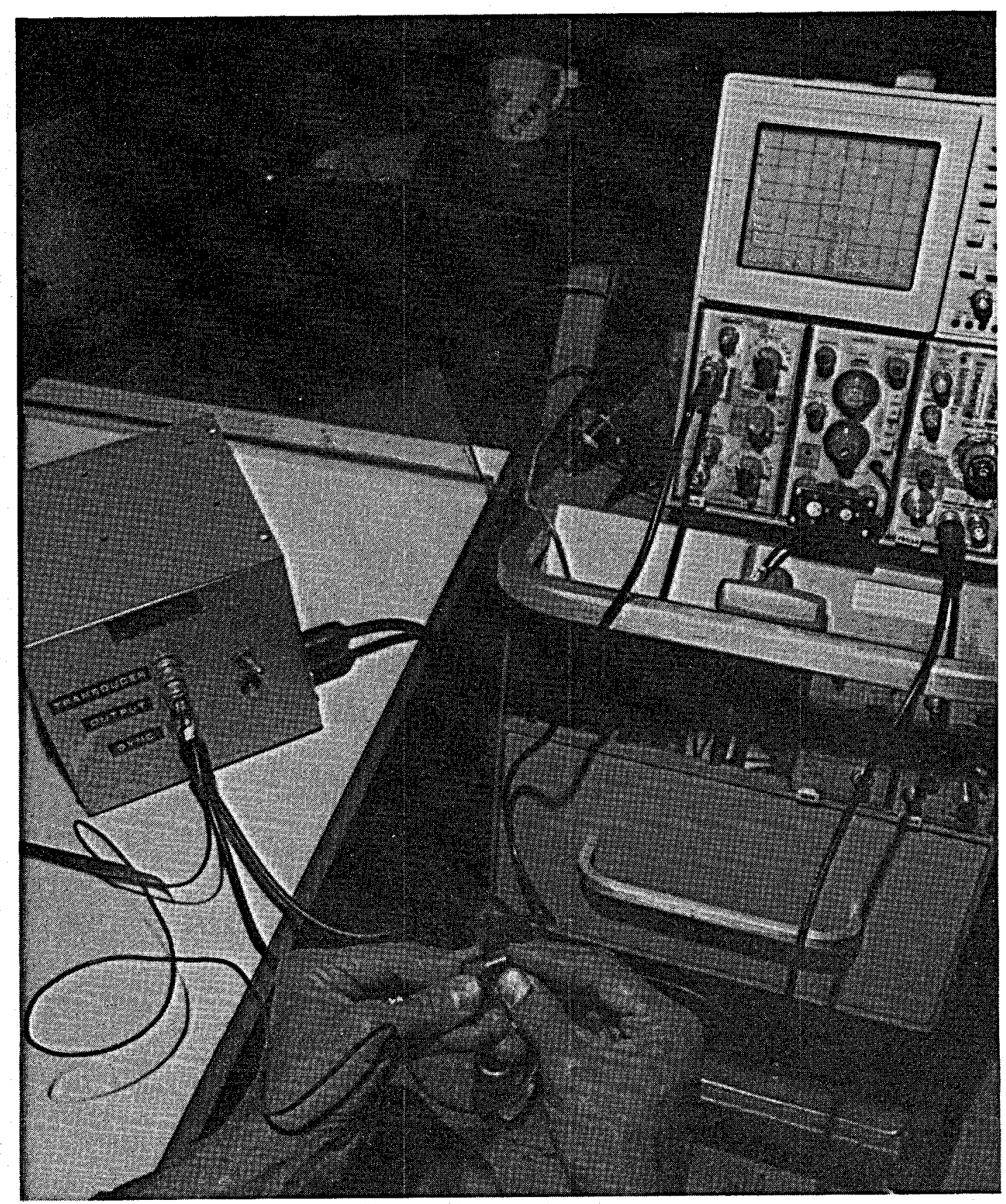

Figure C-1. U1trasonic Test Setup, Showing Oscilloscope, Pulser/Receiver, and Transducer Held Against Cutter Assembly. 


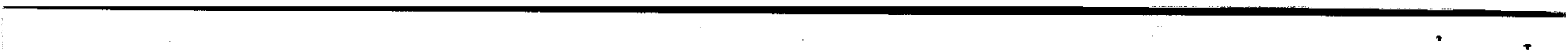




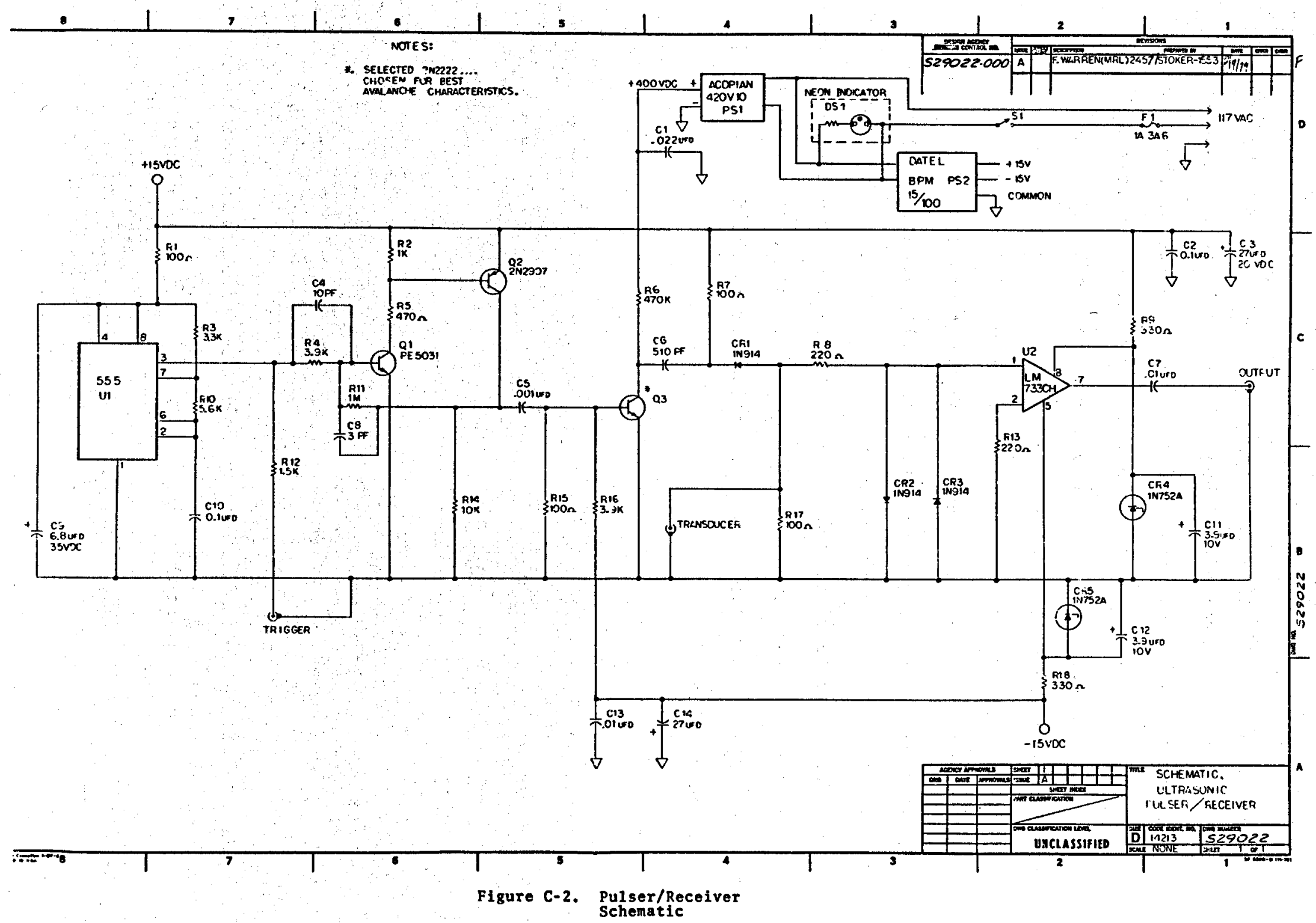


5. Analysis of Test Data

a. Stratapax on steel studs. Picture (a) of Figure C-3 shows the trace obtained from a good bond. The far $1 \mathrm{eft}$ of the scope grid shows the decay of the pulse input to the face of the diamond. The first reflection from the bondline peaks at 0.5 volt and decays to zero within $0.5 \mathrm{\mu sec}$. The second bondline reflection occurs approximately $1.5 \mathrm{\mu sec}$ later with a peak of 0.1 volt.

Picture (b) is the same bond as in picture (a) but the transducer is located in a different area of the diamond surface. The left-hand parts of (a) and (b) are essentially identical, but the low amplitude pulses on the right side of (b) have shifted out in time. These low level pulses are reflections from the back surface of the stud, and the time shift is caused by the change in pulse travel distance resulting from the angle between the Stratapax and stud center 1 ine.

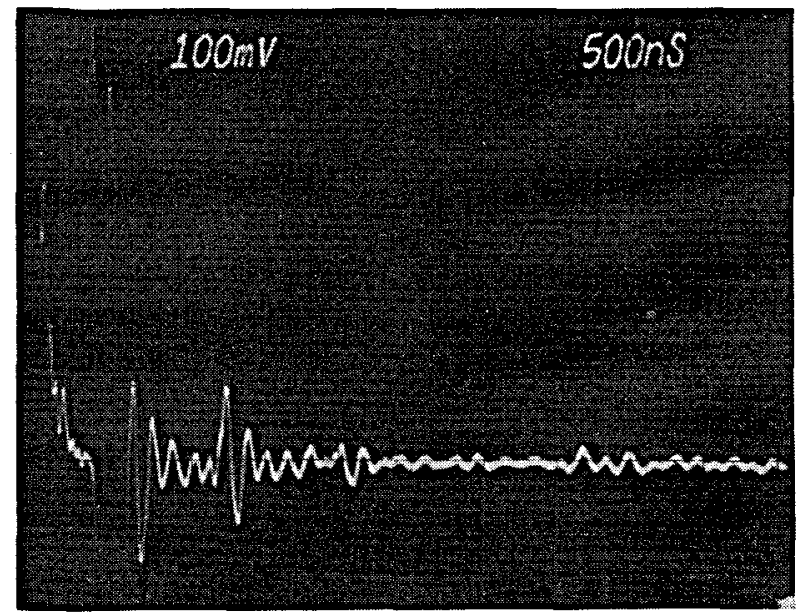

Figure C-3 (a). Good Stratapax to Steel Stud Bond.

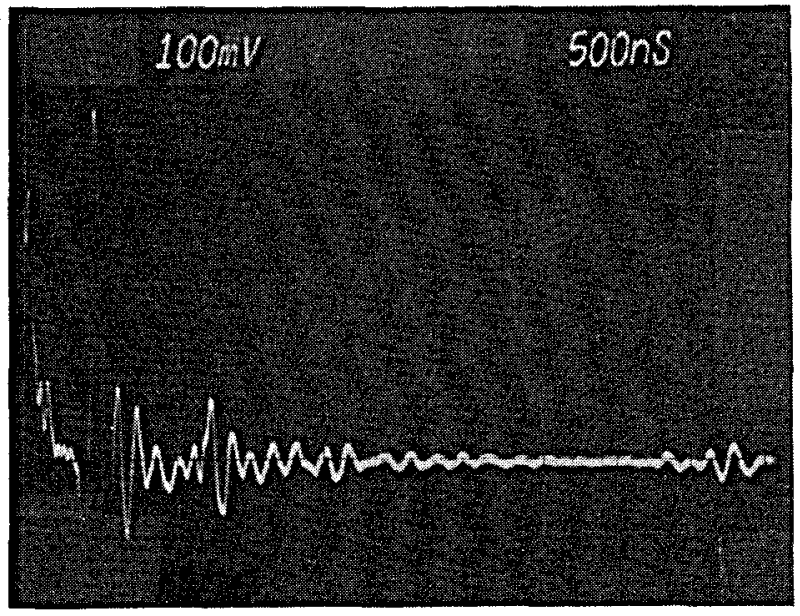

Figure C-3 (b). Same Bond as Figure $\mathrm{C}-3$ (a) but at a Different Point on the Surface. 
- Picture (c) is the same bond but the reduced peaks are due to a change in the quality of the coupling between the transducer and the diamond. Wiping both surfaces clean and starting over again should give peaks similar to (a) and (b).

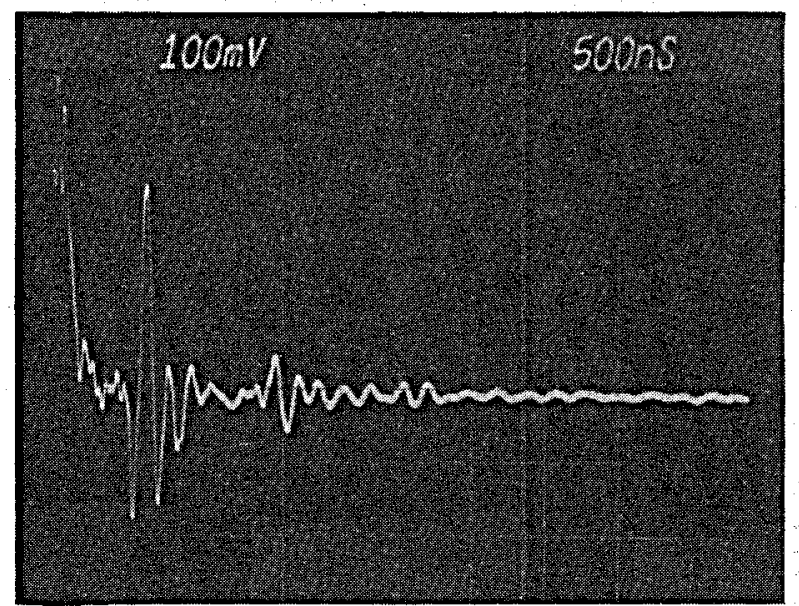

Figure C-3 (c). Same Bond Again, But Poor Coupling Gives Lower First. Reflection.

Picture (d) is a poor diffusion bond where there is essentially no we1d of the Stratapax to the stud, and therefore no energy transfer through the bond interface into the stud. This picture shows that almost all of the energy in the pulse is being reflected between the bond 1 ine and the free Stratapax surface as though there was only air behind the bond.

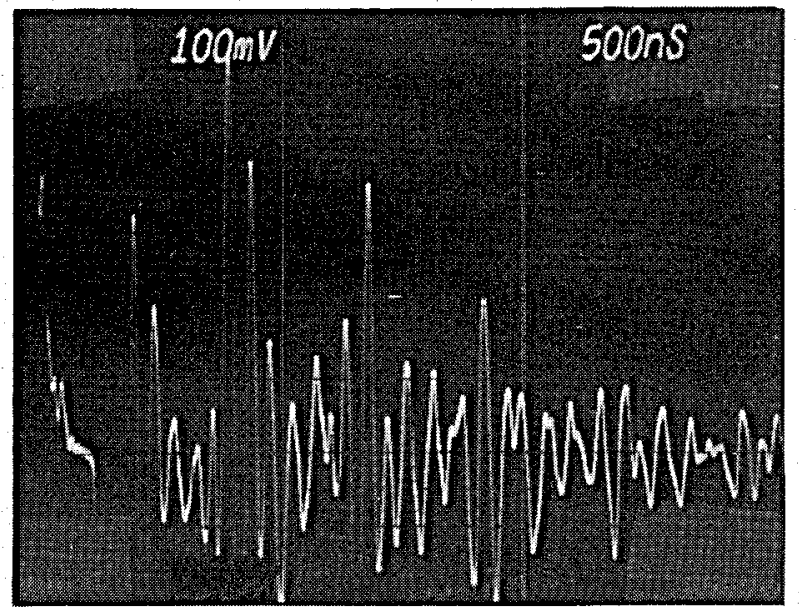

Figure $\mathrm{C}-3$ (d). Poor Bond 
b. Stratapax on carbide studs. Picture (e) of Figure C-3 shows a good Stratapax to tungsten carbide bond. The picture is similar to that of the steel stud except that the peaks are of lower magnitude because of the higher transmissibility of welded surfaces of like material and the resultant lower reflection back to the transducer. The presence of a thin nickel layer between the Stratapax and stud has little effect on the pulse reflections. A poor diffusion bond of a Stratapax on a tungsten carbide stud is essentially the same as for a steel stud. (Figure C-3d)

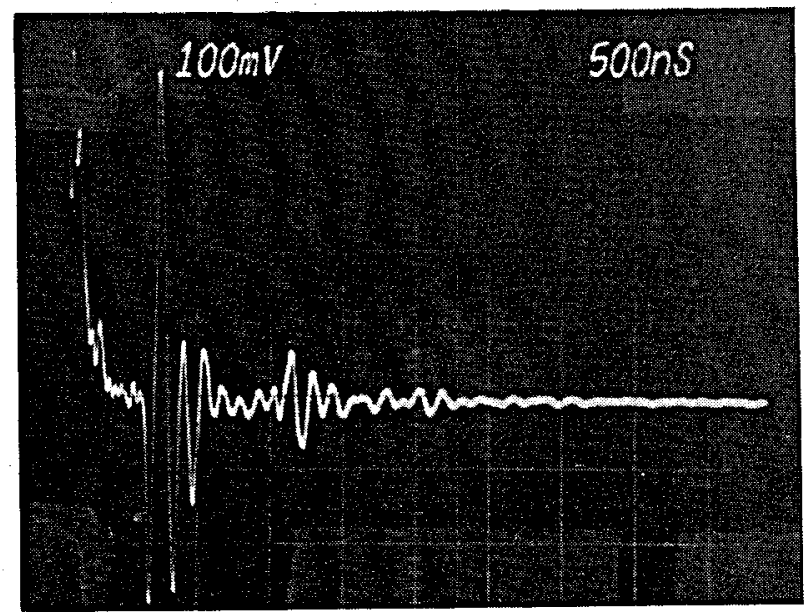

Figure C-3 (e). Good Stratapax to Carbide Stud Bond

\section{Sub-Failure Shear Testing}

To assure that a cutter assembly passing the ultrasonic testing has a bond strength of a specific minimum level, a sub-failure shear strength test should be used. This testing is time consuming but is necessary under the following conditions:

1. Verifying process control of the diffusion bonding, while leaving the cutter assemblies for other testing or actual drill bit use.

2. Using cutter assemblies taken from a HIP container that showed questionable visual results.

3. Assemb1ing a high-reliability drill bit. 
Sandia did only a limited amount of sub-failure shear testing. It is difficult to specify a recommended test level because test variables and unit-to-unit variability normally cause a wide range of measured ultimate shear strengths. An approximate safe level for this test would be $2 / 3$ of the average ultimate strength of a destructive test sample (e.g., if a destructively tested sample of units has ultimate shear strength levels between 35,000 and $45,000 \mathrm{psi}$, it should be safe to test the remainder of the units between 25,000 and 30,000 psi). From Sandia's experience, and using the Sandia fixture, any bond that can take 25,000 psi shear without failing is suitable for drill bit forces.

To gain confidence that the sub-failure testing did not degrade the bond strength, Sandia loaded several cutter assemblies to $75 \%$ of their expected ultimate strength. These loads were then repeated on the same units up to 10 times without failure. The assemblies were next destructively tested, and their ultimate shear strengths fell within the range of strengths of the destructively tested units that had not received sub-failure testing.

\section{DESTRUCTIVE TESTING}

There are three main failure modes when testing bonded drill bit cutter assemblies:

1. Shear failure along the bond line.

2. Fracture failure of the Stratapax.

3. Fracture failure of the WC stud (not applicable to steel studs). The cutter assembly shear fixture used by Sandia is shown in Figure C-4. This fixture has to accommodate cutter assemblies with copper on the rear top stud surface and also studs with reasonable machining tolerances. Thus, there is a considerable amount of bending moment put into a cutter assembly during the shear testing. This bending moment contributes to the fracture failures experienced in the Stratapax and WC stud. 


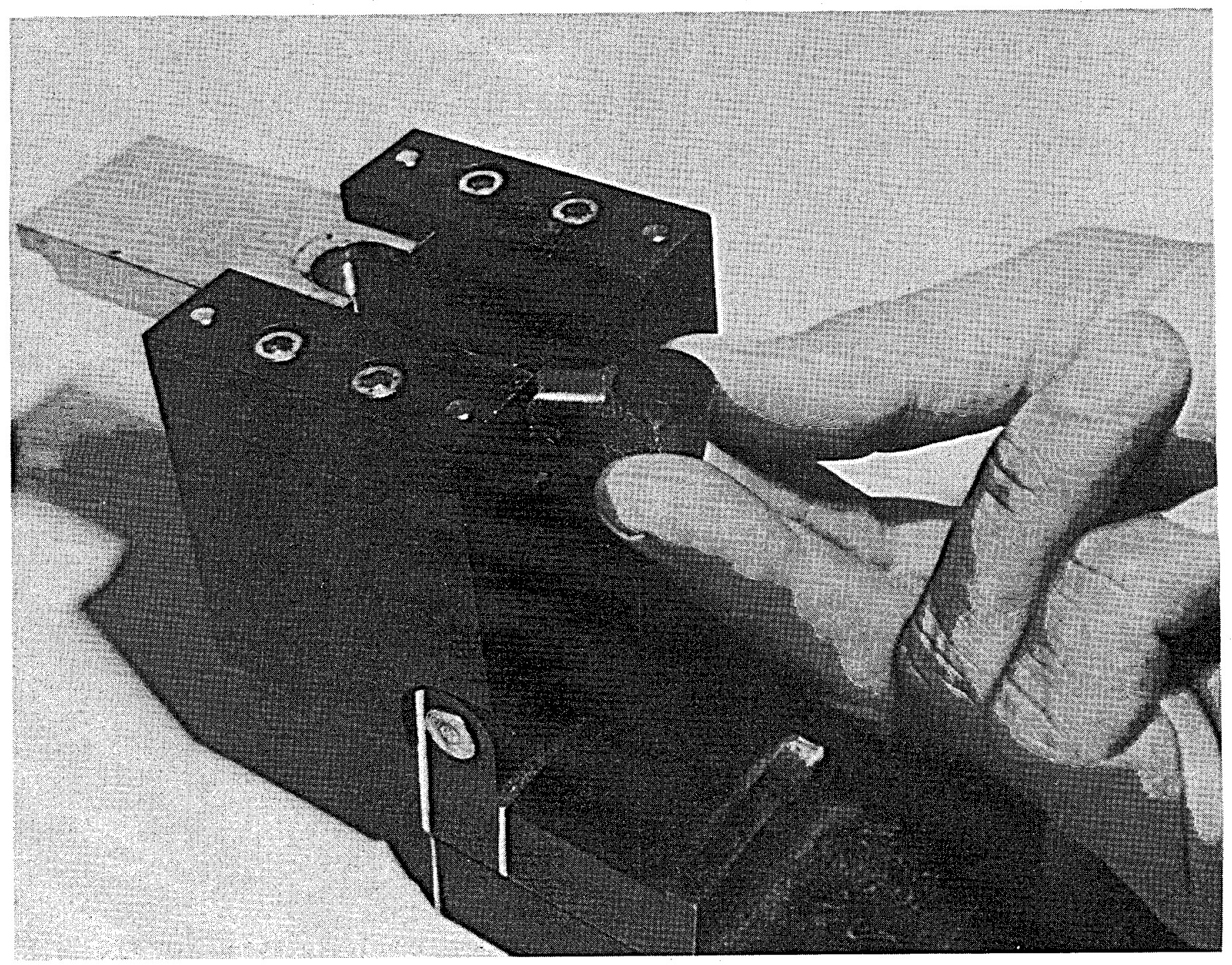

Figure C-4 (a). Placing Cutter Assembly 
Figure C-4 (b) shows the shear fixture ready to be loaded in a laboratory force testing machine. Of course, the laboratory test equipment could be replaced by a simple framework holding a hand-pumped hydraulic cylinder and a pressure gage. Figure C-5 shows typical failed cutter assemblies.

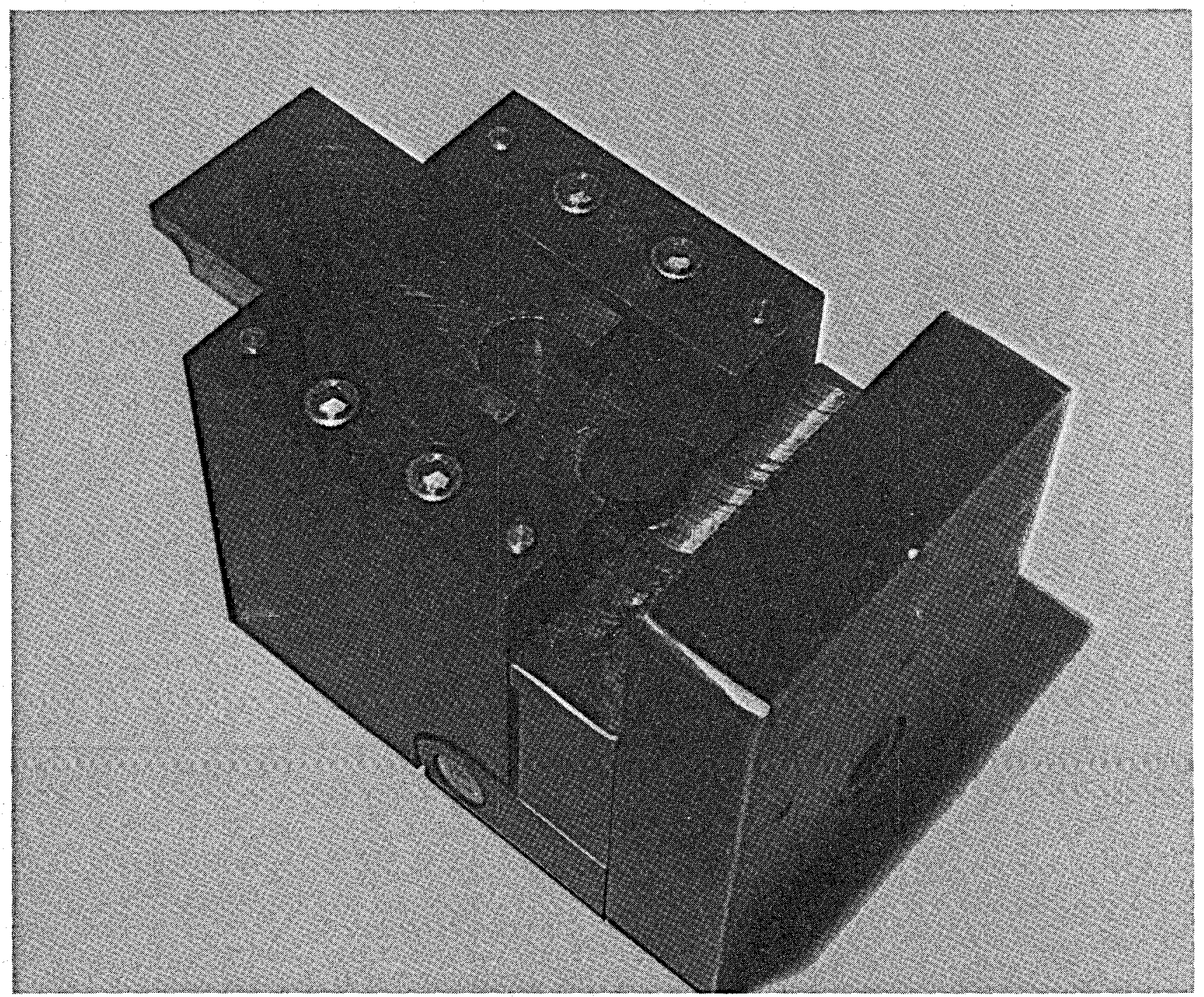

Figure C-4 (b). Shear Fixture Ready for Test. The slide on top is loaded by a calibrated test machine. 


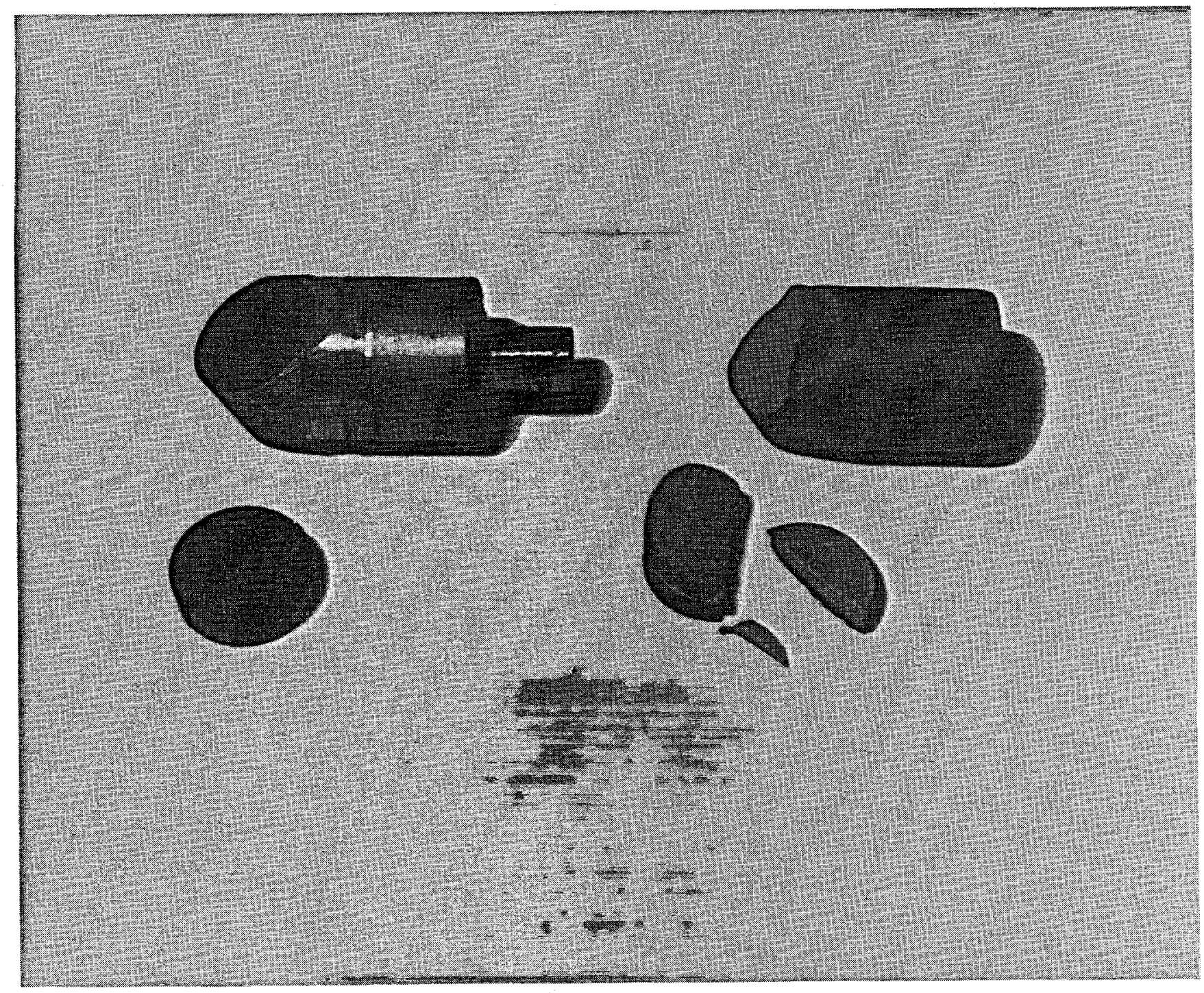

Figure C-5. Failed Cutter Assemblies.

Stee1 stud (left) with

bond line failure; carbide

stud that cracked (right). 


\section{TEST RESULTS}

\section{Genera1}

Sandia roceived some torsional shear test data from GE on the GE high temperature braze (LS braze). Typical ultimate shear values were very high (about $110 \mathrm{kpsi}$ ), but their test method was significantly different from Sandia's. The Sandia fixture introduces a combination of shear and bending and thus gives a lower measured strength than the GE method. Testing at Sandia on GE brazed units showed that the following test results hold for brazed as well as for diffusion bonded cutter assemblies.

\section{Bad U1trasonic Test Results}

If the ultrasonic reflections were similar to the poor bond examples, then the ultimate shear strength was normally near zero but at times reached several kpsi. If a bond shows bad in the ultrasonic test, you can be assured that an actual shear test will verify a defective bond.

\section{Good U1trasonic Test Results}

If the ultrasonic reflections are similar to the good bond examples, then actual shear testing may or may not show that the bond was a strong bond. Good ultrasonic data usually means that the bond strength exceeds $50 \mathrm{kpsi}$. However, if poor process control allows excessive oxides, the shear failure level may be on the order of $15 \mathrm{kpsi}$.

For good, strong diffusion bonds, the push type shear testing used by Sandia will usually result in a broken stratapax rather than a failure in the bond plane. If a carbide stud is used, it may also fracture. If the bonds were good, cutter assembly failures were normally in the 35 to $55 \mathrm{kpsi}$ range. 


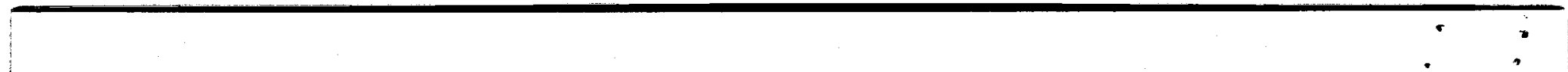


DISTRIBUTION :

TID-4500-R66-UC-66C (507)

Tom Anderson

Venture Innovations

P.0. Box 35845

Houston, Texas 77035

Ed Bingman

She11 Oil Company

Two Shell Plaza

P.O. Box 2099

Houston, Texas 77001

Larry Diamond

Dyna-Dri11

P.0. Box C-19576

Irvine, California 92713

Tom Turner

Phillips Petroleum Company

Geotherma1 Operations

655 East 4500 South

Salt Lake City, Utah 84107

Jim Kingsolver

Geotherma1 Operations

Smith Tool

P.0. Box C-19511

Irvine, California 92713

John C. Rowley

Los Alamos National Labs

Mail Stop 570

Los Alamos, NM 87545

Ed Martin

Superior 0 il

Eastern Division

P.0. Box 51108 OCS

Lafayette, Louisiana 70505

B. J. Livesay

129 Liverpoo1

Cardiff, California 92007

Dr. Melvin Friedman

Professor of Geology

Center for Tectonophysics and Dept. of Geology

Texas A\&्षM University

College Station, Texas $\mathbf{7 7 8 4 3}$
Gene Polk

NL Baroid

6400 Uptown B1vd. N.E., 365W

Albuquerque, NM 87110

James W. Langford

Security Division

Dresser Industries, Inc.

P. 0. Box 24647

Dallas, Texas 75224

John E. Fontenot

NL Petroleum Services

P.0. Box 60087

Houston, Texas 77205

De1 E. Pyle

Union Geotherma1 Division

Union Oil Co. of California

Union Oil Center

Los Angeles, California 90017

William D. Rumbaugh

Research \& Development

Otis

P.0. Box 34380

Dallas, Texas 75234

Dwight Smith

Halliburton

Drawer 1431

Duncan, Oklahoma 73533

Tom Warren

Amoco Production Company

Research Center

p.0. Box 591

Tulsa, Ok1ahoma 74102

H. E. Mallory

P.0. Box 54696

Tu1sa, Ok1ahoma 74155

U.S. Department of Energy

Geothermal Hydropower

Technologies Division

Forresta1 B1dg., CE 324

1000 Independence Ave. S.W.

Washington, D.C. 20585

Attn: J. Bresee

D. Clements

R. Toms

D. A1len 
DISTRIBUTION (cont.) :

Robert Radtke

Strata Bit Corporation

600 Kenrick

Houston, Texas 77060

Charles Huff

PCI

P.O. Box 5551

Midland, Texas 79704

Bruce Walker

Christensen, Inc.

1927 S. Third W.

Salt Lake City, Utah 84119
Morgan Crow
Security Division
Dresser Industries, Inc.
P.0. Box 24647
Dallas, Texas 75224
William Baker, Manager
Research \& Development
Smith Tool
P.0. Box C-19511
Irvine, California 92713
Kenneth Davis
Davis \& Hicks, Inc.
P.0. Box 7906
Midiand, Texas 79703
W. P. Grace, DOE/ALO
3141 L. J. Erickson
3151 W. L. Garner
9000 G. A. Fowler
9344 J. N. Middleton
9700 E. H. Beckner
9730 W. D. Weart
9740 R. K. Traeger
9741 J. R. Kelsey
9741 J. T. Finger
9746 B. Granoff
9747 P. J. Hommert
9750 V. L. Dugan
9760 R. W. Lynch
8214 M. A. Pound
5)

Nuclear \& Geosciences Division
Roy Nicely

Christensen, Inc.

2532 S. $3270 \mathrm{~W}$.

Salt Lake City, Utah 84119

Mike Weichers

Christensen Diamond Tool

P.0. Box 30777

Salt Lake City, Utah 84130

Gerald Boyle

Anco Diamond Composites

545 Fifth Avenue

New York, New York 10017

Bela Geczy

Dyna-Dril1

P.0. Box C-19576

Irvine, California 92713

Mark Thompson

American Coldset Corporation

P.0. Box 615

Addison, Texas 75001

Richard Ridel

NL Hycalog

P.0. Box 60747

Houston, Texas 77205 